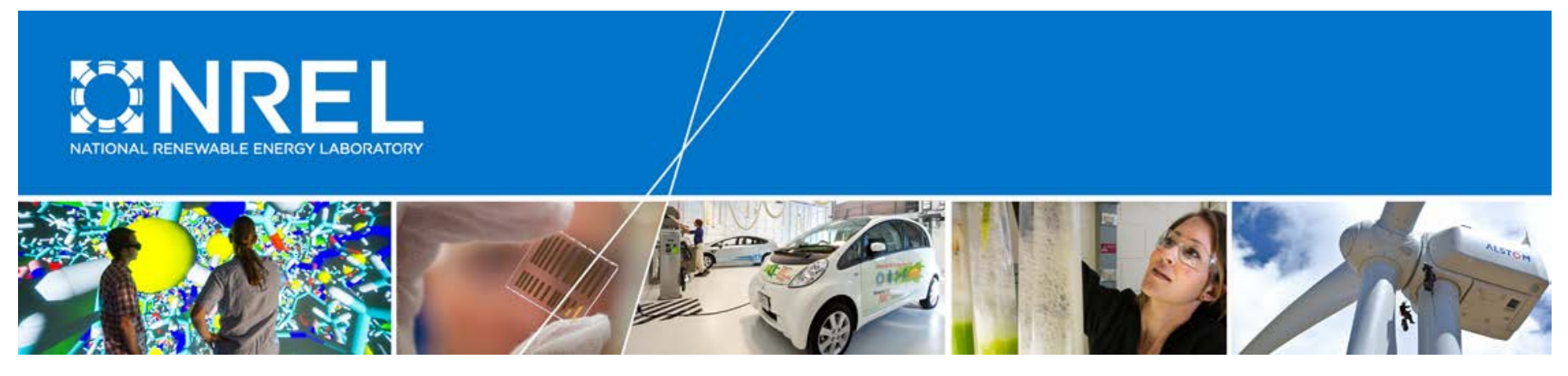

\title{
Use of Low-Temperature Geothermal Energy for Desalination in the Western United States
}

Craig S. Turchi and Sertaç Akar National Renewable Energy Laboratory

Tzahi Cath, Johan Vanneste, and Mengistu Geza Colorado School of Mines

NREL is a national laboratory of the U.S. Department of Energy Office of Energy Efficiency \& Renewable Energy Operated by the Alliance for Sustainable Energy, LLC

This report is available at no cost from the National Renewable Energy Laboratory (NREL) at www.nrel.gov/publications.

Technical Report

NREL/TP-5500-65277

November 2015 


\section{Use of Low-Temperature Geothermal Energy for Desalination in the Western United States}

Craig S. Turchi and Sertaç Akar National Renewable Energy Laboratory

Tzahi Cath, Johan Vanneste, and Mengistu Geza Colorado School of Mines

Prepared under Task No. GTP4.2400
NREL is a national laboratory of the U.S. Department of Energy Office of Energy Efficiency \& Renewable Energy Operated by the Alliance for Sustainable Energy, LLC

This report is available at no cost from the National Renewable Energy Laboratory (NREL) at www.nrel.gov/publications.

\section{Technical Report}

NREL/TP-5500-65277

November 2015

Contract No. DE-AC36-08GO28308
National Renewable Energy Laboratory 15013 Denver West Parkway Golden, CO 80401 303-275-3000 • www.nrel.gov 


\title{
NOTICE
}

This report was prepared as an account of work sponsored by an agency of the United States government. Neither the United States government nor any agency thereof, nor any of their employees, makes any warranty, express or implied, or assumes any legal liability or responsibility for the accuracy, completeness, or usefulness of any information, apparatus, product, or process disclosed, or represents that its use would not infringe privately owned rights. Reference herein to any specific commercial product, process, or service by trade name, trademark, manufacturer, or otherwise does not necessarily constitute or imply its endorsement, recommendation, or favoring by the United States government or any agency thereof. The views and opinions of authors expressed herein do not necessarily state or reflect those of the United States government or any agency thereof.

This report is available at no cost from the National Renewable Energy Laboratory (NREL) at www.nrel.gov/publications.

Available electronically at SciTech Connect http:/www.osti.gov/scitech

Available for a processing fee to U.S. Department of Energy and its contractors, in paper, from:

\author{
U.S. Department of Energy \\ Office of Scientific and Technical Information \\ P.O. Box 62 \\ Oak Ridge, TN 37831-0062 \\ OSTI http://www.osti.gov \\ Phone: 865.576.8401 \\ Fax: 865.576.5728 \\ Email: reports@osti.gov
}

Available for sale to the public, in paper, from:

\author{
U.S. Department of Commerce \\ National Technical Information Service \\ 5301 Shawnee Road \\ Alexandria, VA 22312 \\ NTIS http://www.ntis.gov \\ Phone: 800.553 .6847 or 703.605 .6000 \\ Fax: 703.605.6900 \\ Email: orders@ntis.gov
}




\section{Preface}

This report compiles and summarizes the results for Project 2.5.1.1, "Low-Enthalpy Geothermal Desalination," that were submitted to the DOE Geothermal Technologies Office in milestone reports throughout fiscal year 2015.

\section{Acknowledgements}

This work is a collaborative research project between NREL and researchers in the Advanced Water Technology Center (AQWATEC) at the Colorado School of Mines (CSM) in Golden, Colorado. The CSM team is led by Dr. Tzahi Cath and includes Dr. Johan Vanneste, Dr. Mengistu Geza, and Ms. Bethany Grace Yaffe.

Thanks are given to Science Undergraduate Laboratory Intern (SULI) Jeremy Poe for his investigation of cooling-tower blowdown water sources in 2015. 


\section{Nomenclature or List of Acronyms}

AGMD

AQWATEC

BWRO

CSM

DST

DOE

FCR

GAC

GDsalt

GTO

GUI

IX

MED

MGD

MVC

NF

NREL

O\&M

ORC

$\mathrm{RO}$

SAM

SWRO

TDS

TSS

TVC

USGS

VMD
Air-gap membrane distillation

Advanced Water Technology Center

Brackish-water reverse osmosis

Colorado School of Mines

Decision Support Tool

U.S. Department of Energy

Fixed charge rate

Granular activated carbon

Geothermal Desalination support Tool

Geothermal Technologies Office

Graphical user interface

Ion exchange

Multi-effect distillation

Million gallons per day

Mechanical vapor compression

Nanofiltration

National Renewable Energy Laboratory

Operating and maintenance

Organic Rankine cycle

Reverse osmosis

System Advisor Model

Seawater reverse osmosis

Total dissolved solids

Total suspended solids

Thermal vapor compression

United States Geological Survey

Vacuum membrane distillation 


\section{Executive Summary}

Based on geothermal resource assessment estimates by the U.S. Geological Survey (USGS), total resource capacity for identified hydrothermal systems having mean reservoir temperature between $50^{\circ} \mathrm{C}$ and $90^{\circ} \mathrm{C}$ is over $9,800 \mathrm{MW}_{\text {th }}$. The USGS is revisiting this assessment, and an updated version anticipated in late 2015 or 2016 . Recent presentations by the USGS indicate that the estimated capacity will increase. In total, 13 states have potential for low-temperature hydrothermal resources - with Idaho, Nevada, Arizona, California, and Utah ranking as the highest potential. These areas also overlap with locations of water scarcity and stress.

This joint project between the National Renewable Energy Laboratory and the Colorado School of Mines (CSM) has examined the potential of using low-temperature geothermal resources for desalination. The temperature range in question is not well suited for electricity generation, but can be used for direct heating. Accordingly, the best integration approaches use thermal desalination technologies such as multi-effect distillation (MED) or membrane distillation (MD), rather than electric-driven technologies such as reverse osmosis (RO).

The team developed a decision support tool to assist with the assessment of geothermal-driven desalination. This tool, named "GDsalt," was built on prior work at CSM's Advanced Water Technology Center. The examination of different desalination technologies led to the selection of MD for pairing with geothermal energy. MD operates at near-ambient pressure and temperatures less than $100^{\circ} \mathrm{C}$ with hydrophobic membranes. The technology is modular like RO, but the equipment costs are lower. The thermal energy demands of MD are higher than MED, but this is offset by an ability to run at lower temperatures and a low capital cost. Consequently, a geothermal-MD system could offer a low capital cost and, if paired with low-cost geothermal energy, a low operating cost. The integration of geothermal energy and MD is believed to be capable of achieving a product water cost of less than $\$ 1.5$ per cubic meter.

The economics of desalination remain challenging regardless of technology. For example, the current wholesale cost for small-scale thermal desalination is on the order of $\$ 2-\$ 3 / \mathrm{m}^{3}$, which is at the high end of retail water rates in major U.S. cities. Product water from the new Carlsbad Desalination Project, a large RO plant in southern California, is expected to cost about $\$ 1.7 / \mathrm{m}^{3}$, which is stated to be about twice the cost of alternative water sources. Consequently, desalination is best applied where high-quality product water is valued and the impaired source water requires treatment for disposal. Such a situation provides two sources of "revenue" for the processvaluable product water and avoided treatment costs. The deployment of desalination as a hedge against future water scarcity, despite its relative cost, is sometimes listed as an additional supporting factor.

Based on these considerations, the treatment of cooling-tower blowdown water has been selected as an appealing application for demonstration of geothermal-MD and a potential site has been identified. A proposed field-test project will access cooling-tower blowdown water at a geothermal power plant and use geothermal heat in a small-scale MD process. Objectives include the following:

- Demonstrate the integration of MD with geothermal energy, 
- Develop a performance model and validate membrane flux estimates with commercialscale modules under field conditions at different operating conditions,

- Demonstrate long-term life and performance of the membranes and membrane modules,

- Test and evaluate antiscaling and/or antifouling coatings applied to commercial membranes, and

- Estimate cost of product water based on membrane performance and a sensitivity analysis to the cost of geothermal heat. Define conditions that lead to costs of less than $\$ 1.5 / \mathrm{m}^{3}$ or otherwise provide economic viability. Describe and quantify applications beneficial to the geothermal industry. 


\section{Table of Contents}

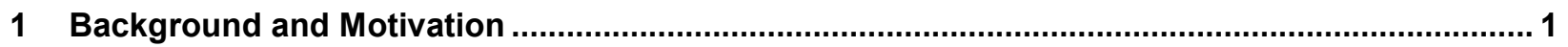

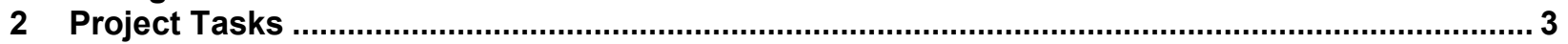

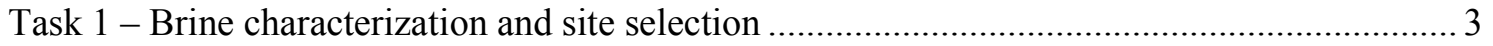

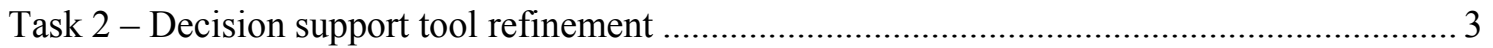

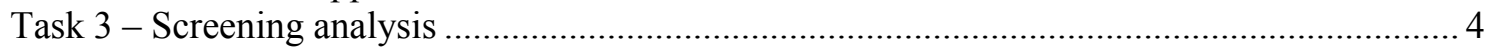

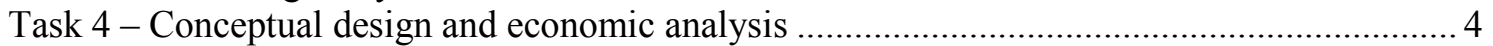

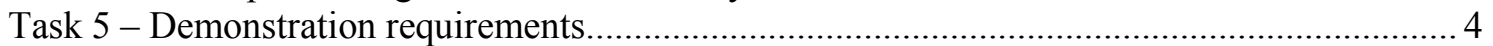

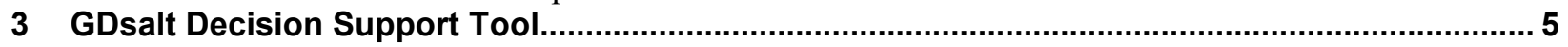

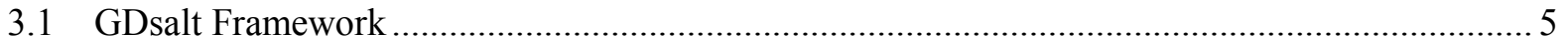

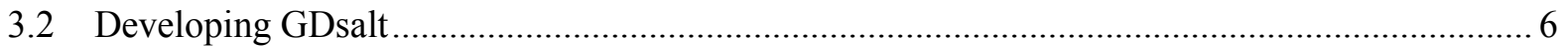

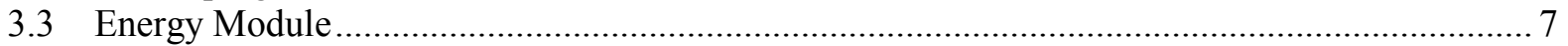

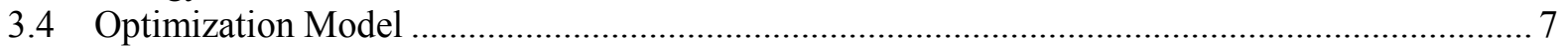

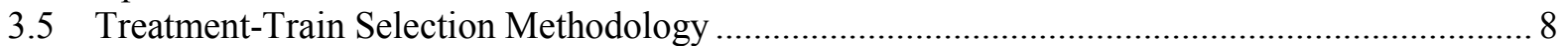

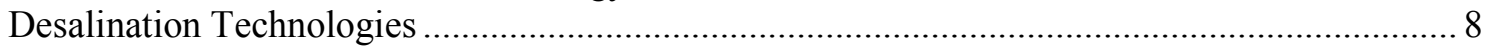

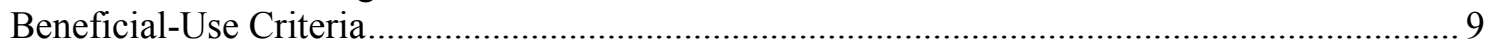

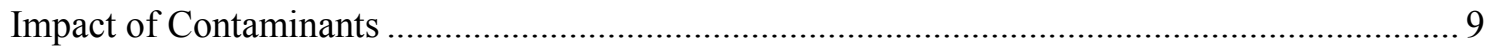

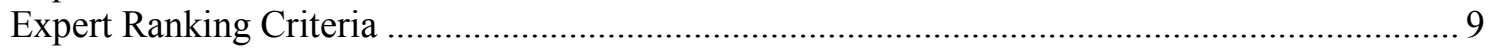

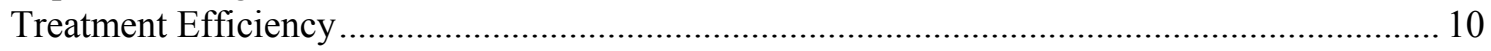

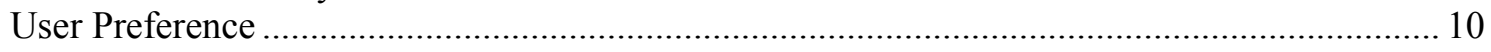

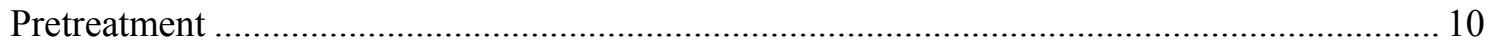

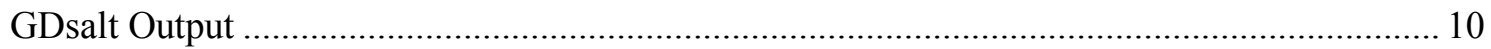

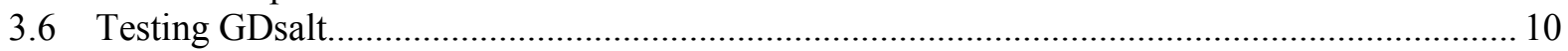

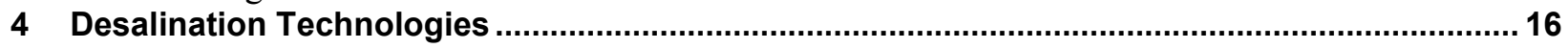

4.1 Thermal Technology Options and Effect of Plant Capacity ................................................... 16

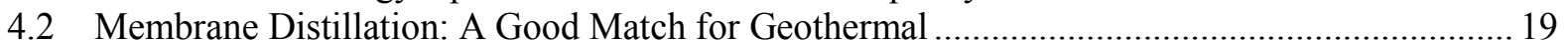

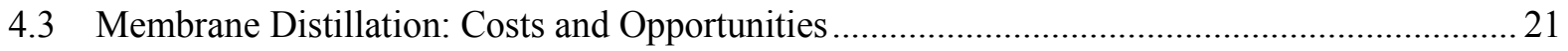

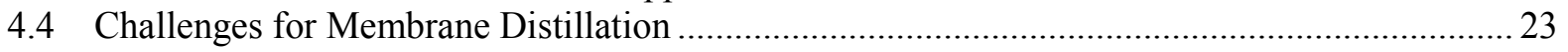

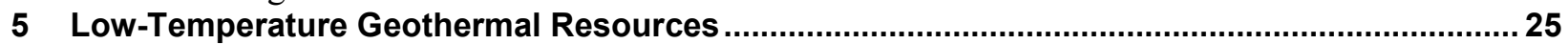

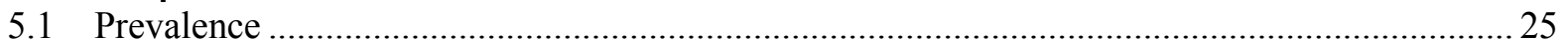

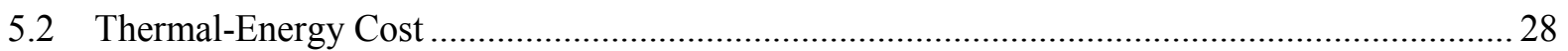

6 Cooling-Tower Blowdown as Source Water for Desalination.................................................. 33

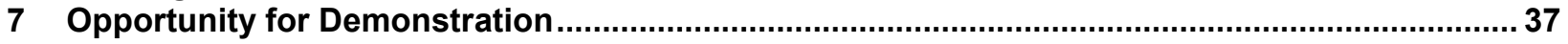

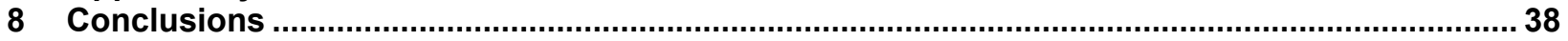

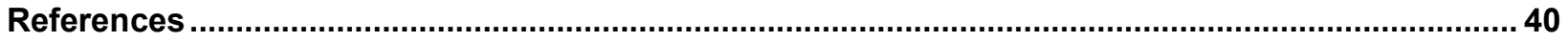

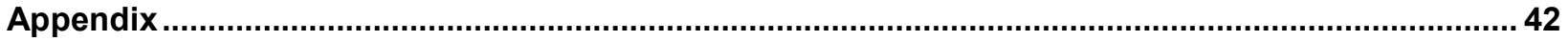

Appendix A - Objectives Categories used in GDsalt..................................................................... 42

Appendix B - Beneficial-Use Water-Quality Requirements .............................................................. 43

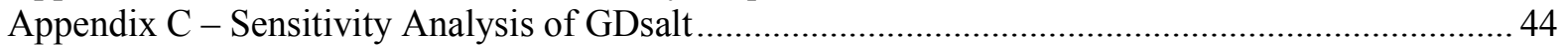

Appendix D - Case Study Provided to CSM Senior Design Class .................................................. 46

Appendix E - Calculation of Levelized Cost of Heat .............................................................. 48 


\section{List of Figures}

Figure 1. Geothermal resource potential based on Southern Methodist University Heat Flow and Western

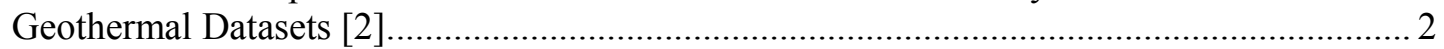

Figure 2. Location and extent of saline aquifers, oil and natural gas production, and coalbed methane reserves; all could be sources of impaired waters [3].

Figure 3. Conceptual framework for selecting a treatment train. Modifications to the pre-existing CSM

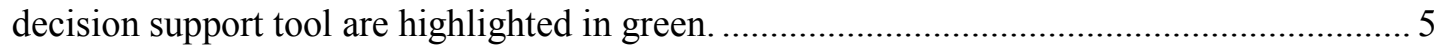

Figure 4. Module data flow for optimization of a treatment train in GDsalt. 5
7

Figure 5. Distribution of cost by category for common desalination technologies [8]. Values are based on

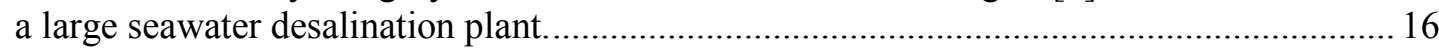

Figure 6. Modular RO and MD desalination technologies are less sensitive to economies of scale than MSF and MED [9]. This makes RO and MD technologies a better match for small plant sizes.

Figure 7. Comparison of two thermal desalination technologies: MED and MD. At either scale, MD exhibits a lower capital cost but greater thermal-energy consumption. Data from [9]. ......... 18

Figure 8 . The combination of modularity and reliance on thermal energy means that MD systems can be the lowest-cost desalination option in small systems if low-cost thermal energy is available. This chart repeats the analysis shown in Figure 6, assuming a tenfold decrease in thermalenergy costs [9].

Figure 9. Basic MD system with a hot source water. Water vapor passes through the membrane from the hot-brine side to the cool-permeate side.

Figure 10. Basic types of membrane distillation: (a) direct-contact MD, (b) air-gap MD, (c) vacuum MD,

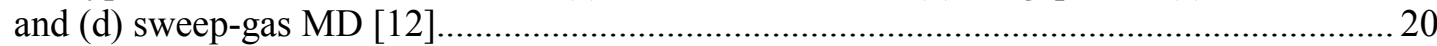

Figure 11. Plot of recovery ratio vs. TDS, showing regions of applicability of different desalination technologies [13]. MD systems can achieve recovery fractions and handle high-TDS waters that RO cannot. The arrows show hypothetical treatment strategies. .................................. 21

Figure 12. Water cost by cost category for MD (left) and MED (right) systems [9]. For MD, overall cost

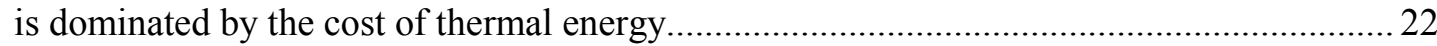

Figure 13. Heat and mass transfer across a membrane [12] .............................................................. 23

Figure 14. Estimated beneficial geothermal heat and desalination potential by states originating from hydrothermal convectional systems [18]. Desalination estimates assume GOR $=4 \ldots \ldots \ldots \ldots . .27$

Figure 15. Distribution of low-temperature (between $50^{\circ} \mathrm{C}$ and $90^{\circ} \mathrm{C}$ ) geothermal wells suitable for MD technology.

Figure 16. LCOH for natural gas boiler and geothermal sources as a function of industrial gas price. The calculation assumes an $80 \%$ boiler efficiency, $90 \%$ availability, and $\$ 270 / \mathrm{kW}_{\text {th }}$ installed capital cost. Geothermal assumptions are listed in Table 6 and Table 7

Figure 17. Typical configuration of a cooling tower at a thermo-electric power plant. The cooling-tower loop interfaces with the turbine's water/steam loop via a heat exchanger. Water consumption comes from evaporation, blowdown, and to a lesser extent, loss of water droplets as drift [24]. .33

Figure 18. Total annual cooling tower blowdown volume for the eight western states in this study as a function of assumed cycles of concentration. 34

Figure 19. Estimated blowdown water volume as a function of assumed cycles of concentration for each western state.

Figure 20. Google Maps overlay of thermo-electric power plants in the western United States that use cooling towers. The colors and sizes displayed represent estimated blowdown-water flow rates. (C) 2015 Google, Map Data....... 


\section{List of Tables}

Table 1. GDsalt Module description with changes made to the original CSM tool ................................. 6

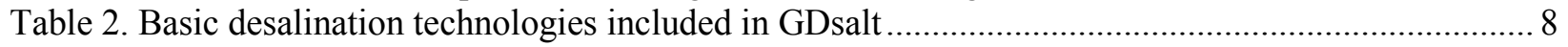

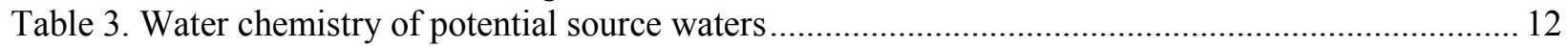

Table 4. Water-quality requirements for selected beneficial uses ........................................................ 13

Table 5. Distribution of geothermal beneficial heat and mean resource energy by state for hydrothermal convectional systems having mean reservoir temperature between $50^{\circ} \mathrm{C}$ and $90^{\circ} \mathrm{C}$ (Original

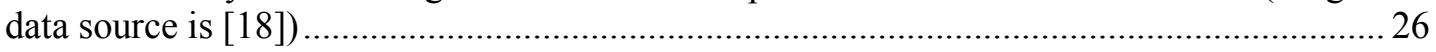

Table 6. Summary of LCOH estimates for different production scenarios from new geothermal wells*.. 29

Table 7. Summary of LCOH estimates for different production scenarios from existing geothermal wells

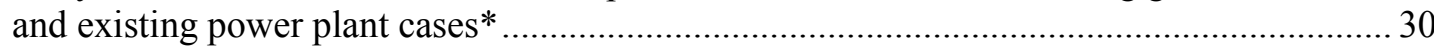

Table 8 . Estimated annual blowdown volume by state in billion gallons per year for different assumed

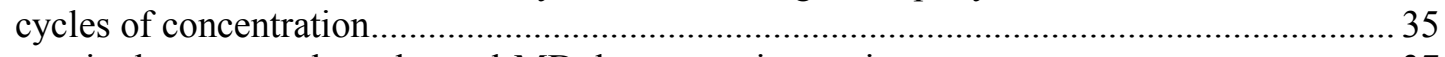

Table 9. Partners in the proposed geothermal-MD demonstration project .......................................... 37

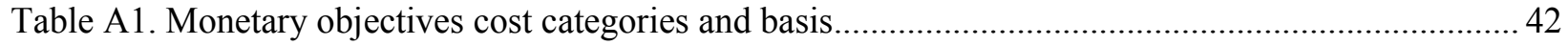

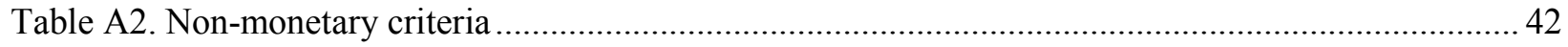

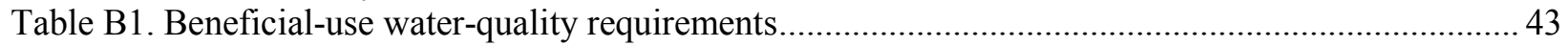

Table C1. GDsalt results for Imperial Valley groundwater - effect of specified recovery ....................... 44

Table C2. GDsalt results for Imperial Valley - effect of specified recovery......................................... 45

Table C3. GDsalt results for Hidalgo County, TX groundwater - effect of specified recovery................. 45 


\section{Background and Motivation}

Geothermal resources are primarily located in the western United States and are often divided into high-temperature and low-temperature resources. In general, high-temperature resources are suitable for power generation at utility scale (i.e., $>5 \mathrm{MW}$ ). At the low-temperature end of the spectrum, e.g., less than about $100^{\circ} \mathrm{C}$, resources may be suitable for small-scale power generation, but are more readily useful for direct-use applications (e.g., space heating, greenhouses). The low-temperature resource base is more widely distributed and is also highly underutilized. Therefore, finding alternative uses for the low-temperature resource base- beyond small-scale, distributed power generation and typical direct-use applications-is important to the adoption of geothermal energy as a long-term, sustainable option in the U.S. energy portfolio. Ultimately, this is the impetus of this study.

The desalination of impaired waters is a potentially useful application of low-enthalpy geothermal energy, for example, from low-temperature resources or rejected heat from hightemperature geothermal power plants. Desalination, and more specifically thermal desalination, is one potential direct-use application of low-temperature geothermal energy sources. A viable geothermal desalination application must meet several criteria:

1. Have an available source of geothermal energy at low cost.

2. Have impaired source water that can be processed via one or more pretreatment and desalination processes to create a beneficial product water. Potential source waters include: brackish surface or groundwater, seawater, brines co-produced from oil and gas operations, industrial wastewater, and agriculture drainage water. In some instances, the geothermal brine itself could be used as the source water.

3. Have a suitable user or market for the product water to justify the investment and operating costs.

Substantial declines in potable groundwater have been observed across the United States in the past decade [1]. Along with water conservation measures, desalination is gaining attention throughout the United States as an alternative fresh-water source to hedge against future drought and water shortages due to population growth, weather patterns, and climate change. In the West, many of the aquifers experiencing the highest declines are situated in areas where geothermal resources coexist (Figure 1). Additionally, a number of these areas are collocated with impaired waters (Figure 2).

The concept explored in this study is that heat from low-enthalpy geothermal sources can be directly used in thermal desalination processes. This project evaluated the technical feasibility of combining desalination technology with available low-enthalpy heat to produce high-quality water that would be of beneficial use for local consumers. This report covers progress that occurred on the project during FY14 and FY15.

The project was undertaken as a collaborative effort between the National Renewable Energy Laboratory (NREL) and researchers within the Advanced Water Technology Center (AQWATEC) at the Colorado School of Mines (CSM) in Golden, Colorado. 
SMU Geothermal Laboratory Heat Flow Map of the Conterminous United States, 2011

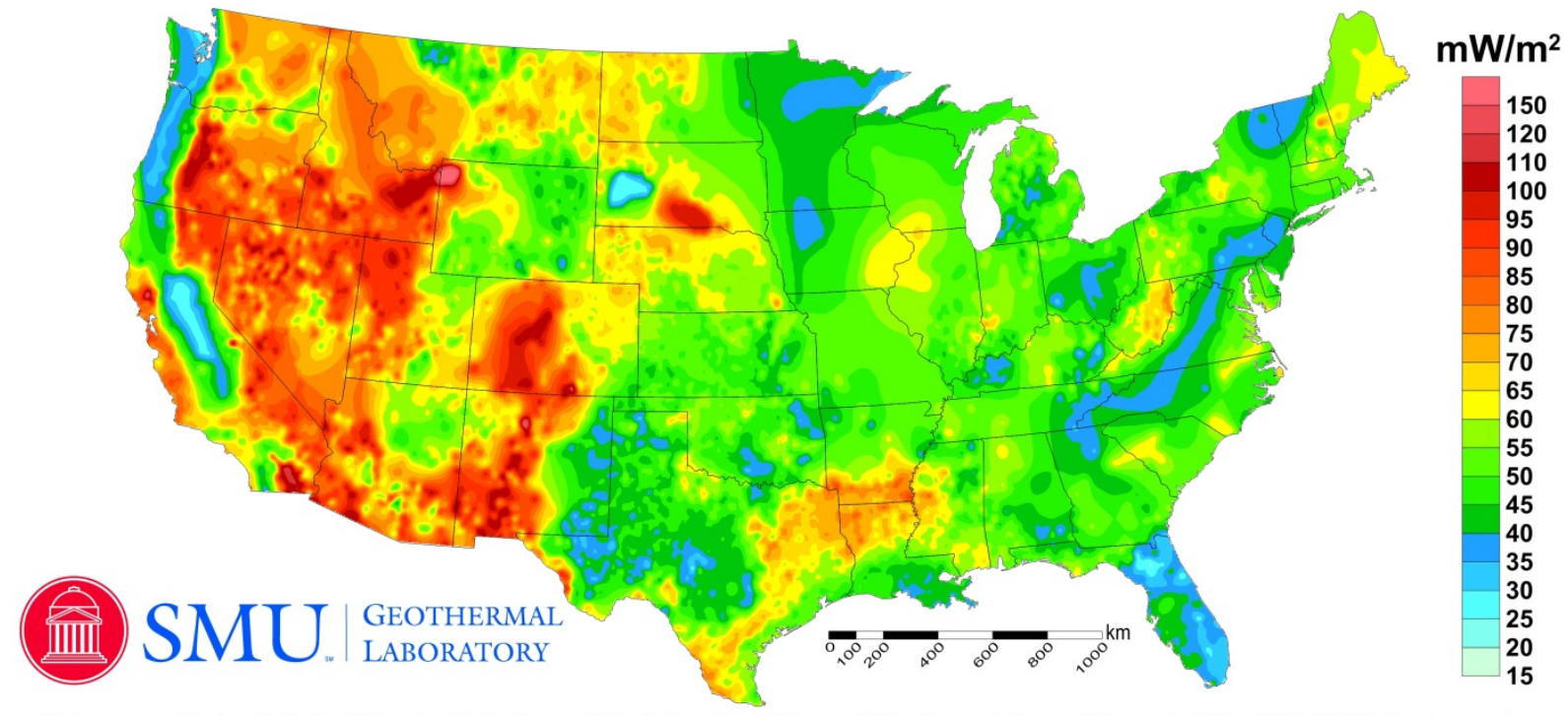

Reference: Blackwell, D.D., Richards, M.C., Frone, Z.S., Batir, J.F., Williams, M.A., Ruzo, A.A., and Dingwall, R.K., 2011, "SMU Geothermal Laboratory Heat Flow Map of the Conterminous United States, 2011". Supported by Google.org. Available at http://www.smu.edu/geothermal.

Figure 1. Geothermal resource potential based on Southern Methodist University Heat Flow map.

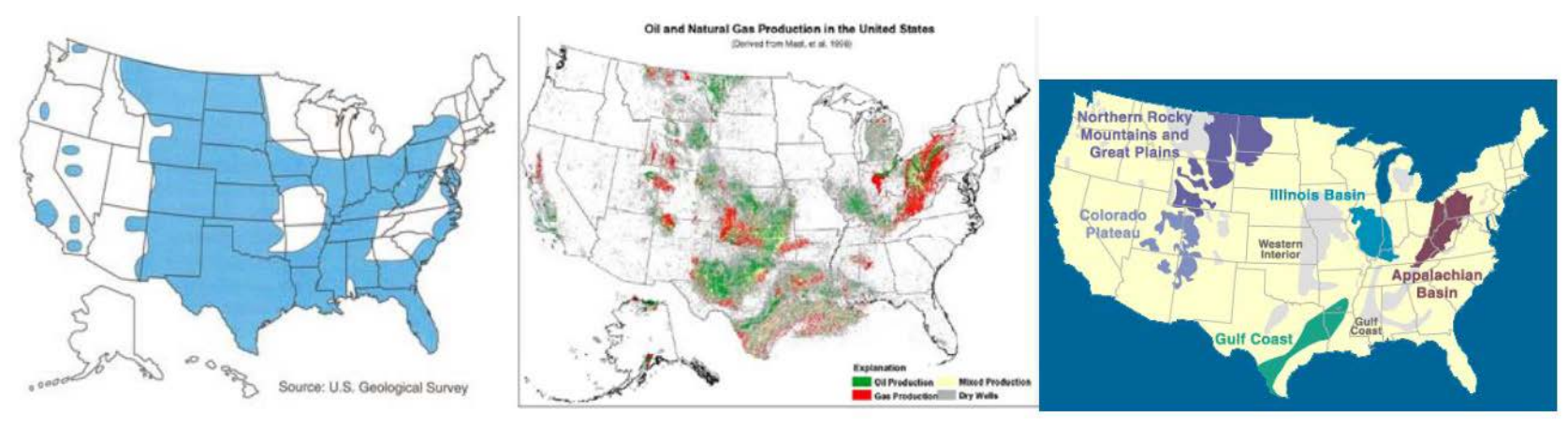

Figure 2. Location and extent of saline aquifers, oil and natural gas production, and coalbed methane reserves; all could be sources of impaired waters [2]. 


\section{Project Tasks}

The goal of the project was to provide the U.S. Department of Energy's (DOE's) Geothermal Technologies Office (GTO) with insight on the potential impacts and technology challenges related to geothermal-assisted desalination. The data collected and tools developed in the project will also be valuable to stakeholders, allowing them to identify efficient and suitable desalination processes based on site-specific constraints. Outcomes of this project include:

- Adaptation of an existing decision support tool capable of identifying suitable treatment trains (i.e., desalination and pretreatment processes) based on impaired water quality, the type and quantity of energy needed for desalination, and desired water quality for beneficial use;

- Identification of collocated geothermal and impaired water resources that could meet the identified energy demand;

- Conceptual designs and thermal analysis of the integration of geothermal and desalination technologies for selected sites;

- Identification of candidate sites for a demonstration project; and,

- An engineering gap assessment to determine if further research and development (R\&D) is required before this concept can be adopted.

The project was divided into five tasks, as described next.

\section{Task 1 - Brine characterization and site selection}

Water chemistry data for impaired waters were collected and analyzed to determine water type (i.e., classification) using a standard approach used by the groundwater industry. The data were then analyzed to determine a reasonable subset of locations that will be used throughout the rest of the study. Water-quality data were used as an input to Task 3 . This task was completed in December 2013. The results were documented in a November 2014 milestone report to DOE and are reviewed in Appendix C.

\section{Task 2 - Decision support tool refinement}

An existing decision support tool developed by CSM was modified to incorporate the inputs necessary to complete the geothermal desalination screening selection task. The tool already contained information regarding current desalination technologies and pretreatment processes that allow it to calculate product water quality based on source water chemistry and treatment method. New inputs included the results of the brine characterization task and resource temperature for the selected site. The tool outputs suggested desalination technologies (and pretreatment processes) that can be used for given source water and the energy (heat and electricity) required to complete the desalination process. The revised tool has been designated as the geothermal desalination support tool or "GDsalt." 


\section{Task 3 - Screening analysis}

The screening analysis used GDsalt to determine if selected sites were viable options for adoption of geothermal desalination technology. The screening analysis focused on geothermal sites that were collocated with impaired water, whether it be surface or groundwater, seawater, or geothermal and/or co-produced brines. The screening analysis also considered desired beneficial use (which is a GDsalt input), because if a user needs certain water but the technology cannot provide it given the input water type/quality, then the site would be eliminated from consideration for potential demonstration. The screening analysis identified the best desalination options for integration with low-temperature geothermal energy.

\section{Task 4 - Conceptual design and economic analysis}

After the sites were screened and the most promising technologies identified, a conceptual design was developed for representative locations. This task objective was pursued through a relationship with the senior design course instructors in the Chemical \& Biological Engineering Department at CSM. An example geothermal-desalination demonstration plant was modeled by the senior design class using Aspen simulation software to estimate the system performance and cost. NREL and the GDsalt team mentored the senior design project team to provide context for the project. The completed class project helped test and validate GDsalt.

\section{Task 5 - Demonstration requirements}

The identification of requirements for geothermal desalination was followed by locating a potential test site for a field demonstration. This demonstration was proposed as follow-on work under the FY16 "Lab Call" research solicitation from the GTO. 


\section{GDsalt Decision Support Tool}

Selection of water desalination processes is a complex task, and it can include assessment of dozens of desalination and pretreatment technologies [3]. It involves developing a treatment train that comprises a desalination technology and pretreatment processes (in both cases, there can be one or more technologies) based on input water quality and quantity and the target end-use quality. A computerized decision support tool is a good way to "automate" this process to identify the best candidate treatment train(s) based on user-defined inputs such as water quality, treatment efficiency, energy type available, energy demand limitations, and overall economics (i.e., capital and operations and maintenance (O\&M) costs). The objective of the GDsalt tool developed as part of this study was to identify suitable treatment trains based on input water quality and quantity, intended use of the treated water (beneficial use), and geothermal resource capacity, as specified by the user. GDsalt is not meant to replace an engineering design - it is a broad estimation tool that suggests one or more reasonable treatment trains that would meet the user's main requirements. If the user wishes to pursue one of the suggested options, the next step would be a more detailed engineering assessment.

\subsection{GDsalt Framework}

GDsalt's objective function includes monetary and non-monetary objectives. The monetary objectives include the total capital cost and annual O\&M costs. Initial capital costs of investment and O\&M costs for each treatment technology are calculated based on other inputs such as plant size and chemical demand. The tool also accounts for non-monetary objectives using a user- and expert-ranking approach that allows users to enter weightings regarding each treatment method with respect to a list of non-monetary criteria such as footprint, modularity, or skill requirement. The monetary and non-monetary criteria are finally combined into a single objective function. GDsalt determines suitable treatment trains in terms of the user-defined objectives while meeting target water-quality constraints. A conceptual representation of GDsalt is provided in Figure 3; more detail is provided in Appendix A.

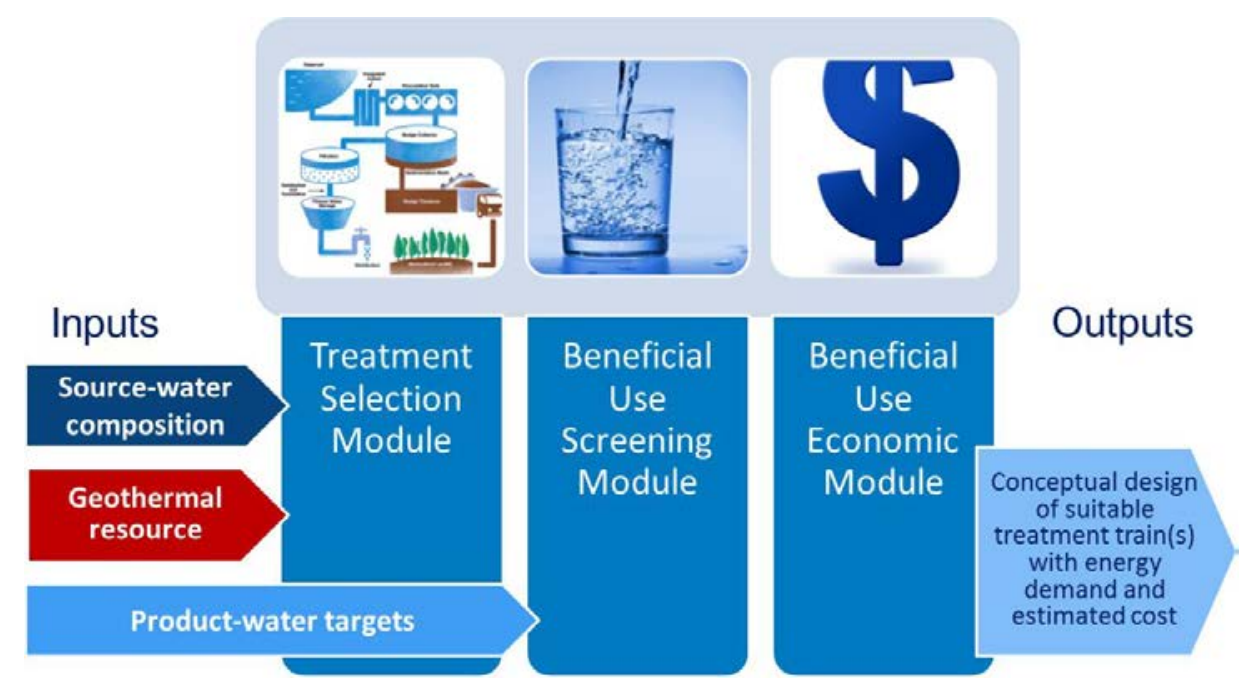

Figure 3. Conceptual framework for selecting a treatment train. Modifications to the pre-existing CSM decision support tool are highlighted in green. 
Several constraints have to be met by GDsalt during the treatment technology selection process. One of the constraints is achieving the water-quality requirements for the intended beneficial use as defined by established water-quality standards. Based on feedwater quality and target water requirements, the tool calculates the constituents requiring removal and the level of required treatment. The tool can access a built-in database of feedwater quality for different source water types or allow users to input their own water-quality data. The tool's database also includes the level of treatment required for each beneficial-use category. The graphical user interface (GUI) allows the user to select source water-type and targeted beneficial-use category. The beneficialuse options include: potable water, livestock watering, industrial, commercial, agricultural irrigation, fisheries and wildlife maintenance and enhancement, recreation, fire protection, dust suppression, and more. Other constraints that affect the selection of treatment technologies are also included in GDsalt. These include the ability for the user to include or exclude specific treatment technologies based on site-specific conditions and allowing GDsalt to optimize additional technologies that are required. Constraints can also be defined to limit the use of certain technologies based on source-water type or type of energy source for desalination. In this fashion, one can configure GDsalt to favor technologies that work best with the geothermal resource in question.

\subsection{Developing GDsalt}

This study upgraded and modified a tool developed by CSM that was originally used to investigate treatment of produced water from coalbed methane operations [3]. The basic decision support tool comprises four modules: 1) Water Quality, 2) Treatment Selection, 3) Beneficial Use, and 4) Economics. This existing tool lacked the ability to determine and optimize energy source (heat and/or electricity) necessary to treat a given input water type to the desired beneficial use, as well as the ability to optimize the treatment train selection around several objective functions and constraints. Therefore, a number of modifications were made to address these issues in the new geothermal desalination support tool (GDsalt). The primary changes are outlined in Table 1.

Table 1. GDsalt Module description with changes made to the original CSM tool

\begin{tabular}{|c|c|c|}
\hline Module & Original Support Tool & GDsalt Modifications \\
\hline $\begin{array}{l}\text { Source } \\
\text { Water } \\
\text { Quality }\end{array}$ & $\begin{array}{l}\text { - Location, chemical constituent, and flow } \\
\text { rate data for select hydrocarbon } \\
\text { resources }\end{array}$ & $\begin{array}{l}\text { - Same data parameters but for } \\
\text { groundwater, surface water, seawater, } \\
\text { and produced water located near } \\
\text { geothermal resources }\end{array}$ \\
\hline $\begin{array}{l}\text { Treatment } \\
\text { Selection }\end{array}$ & $\begin{array}{l}\text { - } 32 \text { desalination technologies and } \\
\text { associated pretreatment processes } \\
\text { - All of the technologies included in } \\
\text { GDsalt are commercially available and } \\
\text { the processes thoroughly vetted [3]. } \\
\text { - Expert ranking that can be user defined; } \\
\text { default emphasis was on cost and } \\
\text { treatment efficiency }\end{array}$ & $\begin{array}{l}\text { - Updates to expert ranking process } \\
\text { within the tool to account for energy- } \\
\text { demand module } \\
\text { - Integration of the optimization model to } \\
\text { improve decision process and allow } \\
\text { fewer assumptions about user-specified } \\
\text { inputs }\end{array}$ \\
\hline $\begin{array}{l}\text { Beneficial } \\
\text { Use }\end{array}$ & $\begin{array}{l}\text { - Drinking, livestock, agriculture, and } \\
\text { industrial water-quality requirements }\end{array}$ & - None \\
\hline
\end{tabular}




\begin{tabular}{|l|l|l|}
\hline Module & Original Support Tool & GDsalt Modifications \\
\hline Economics & $\begin{array}{l}\text { - Capital and O\&M cost information for } \\
\text { the various desalination and } \\
\text { pretreatment technologies }\end{array}$ & $\begin{array}{l}\text { - Updated capital and O\&M cost } \\
\text { information }\end{array}$ \\
\hline $\begin{array}{l}\text { Energy } \\
\text { Demand }\end{array}$ & - Did not exist & $\begin{array}{l}\text { - Specify energy type (electricity and } \\
\text { heat) and demand }\end{array}$ \\
\hline
\end{tabular}

\subsection{Energy Module}

A key change in GDsalt was calculating the amount of energy (heat and electricity) required to complete the pretreatment and desalination processes based on input water quantity and quality, treatment efficiency, and desired beneficial use. This energy demand can be compared directly with the collocated geothermal resource capacity (electricity or thermal energy) to determine if the geothermal energy can meet the demand.

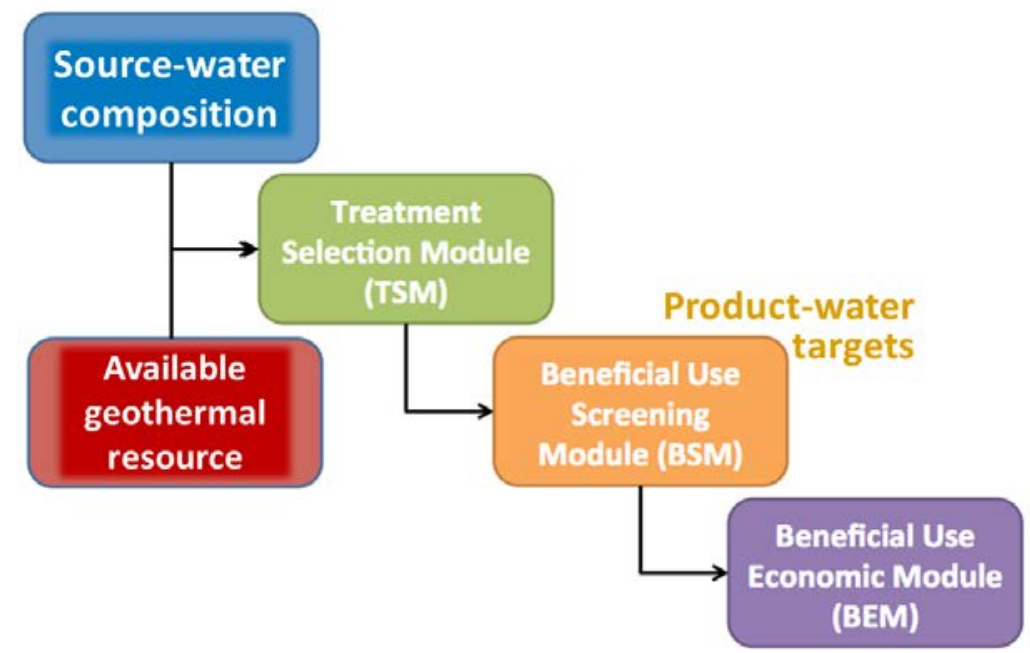

Figure 4. Module data flow for optimization of a treatment train in GDsalt.

\subsection{Optimization Model}

The other major modification to GDsalt was addition of an optimization model to the decision process (green box in Figure 3). As stated above, selection of treatment technologies is influenced by several criteria, both monetary and non-monetary. Thus, the treatment selection was approached by combining these criteria into a single "objective function" and approaching the solution as an optimization problem. This method allowed inclusion of multiple criteria and can be applied with one or more constraints. Multi-objective optimization techniques can resolve conflicting objectives (such as low installed cost vs. low life-cycle cost), which may require a trade-off between different objectives. In this study, we introduced multiple monetary and nonmonetary criteria (see Appendix A). The non-monetary criteria were assigned numerical weighting values based on default or user-defined scores. For example, a treatment technology may have relatively low capital and O\&M costs, but may require a larger footprint than desired or special operator skills that are scarce.

When dealing with multiple conflicting objectives, the solution can be seen as optimal when no objective value can be improved without impairing some other objective. Converting individual 
objectives into a single objective function allows the problem to be solved by minimizing or maximizing this function. When the objectives included in the multi-objective problem are both quantitative and qualitative, normalization is needed. The weighted-sum method allows the multi-objective optimization problem to be cast as a single-objective mathematical optimization problem. This single-objective function was constructed as a sum of objective functions multiplied by weighting coefficients. Weights were applied by the user to each criterion based on AQWATEC's professional judgment regarding the importance of each objective to the decision making. A criterion can be totally excluded if the user assigns a score of zero. Thus, one or many of the criteria summarized in Tables A1 and A2 can be used in the selection process.

Other modifications and updates were made to the original modules to improve the performance of GDsalt and the precision of results. These include: ability for the user to include or exclude a pretreatment process or a desalination technology based on site-specific needs, modification to use quantitative values for criteria that can be quantified (e.g., capital, O\&M cost, energy demand), flexibility to use a single criterion (e.g., energy demand or cost), or a combination of multiple criteria, and improvements in the user interface.

\subsection{Treatment-Train Selection Methodology}

GDsalt is intended to select suitable treatment trains with respect to monetary and non-monetary criteria while meeting the water-quality requirements and other constraints. The following section lists some of the components available within GDsalt.

\section{Desalination Technologies}

GDsalt includes several desalination technologies; the major types are listed in Table 2. The preferred desalination process is selected using the optimization procedure. Total dissolved solids (TDS) concentration is used for preliminary screening of the desalination processes. TDS is the amount of dissolved inorganic and organic constituents in water and is also referred to as salinity. In this module, TDS is calculated based on the summation of ions present in the water; however, in most cases, TDS can also be estimated based on the electrical conductivity of a water sample. The constraint is defined such that the salts are removed to the level required by the beneficial use. In some cases, where the TDS is very low, the tool will point out that desalination is not required and will provide an alternative list of technologies to deal with specific contaminants that may exceed water standards.

Table 2. Basic desalination technologies included in GDsalt

\begin{tabular}{|l|c|c|}
\hline Desalination Technology & $\begin{array}{c}\text { Electric } \\
\text { Energy } \\
\text { Required }\end{array}$ & $\begin{array}{c}\text { Thermal } \\
\text { Energy } \\
\text { Required }\end{array}$ \\
\hline Electrodialysis & $\checkmark$ & \\
\hline Membrane distillation & $\checkmark$ & $\checkmark$ \\
\hline Thermal distillation & $\checkmark$ & $\checkmark$ \\
\hline $\begin{array}{l}\text { FO-RO hybrid (hybrid of forward osmosis and reverse } \\
\text { osmosis) }\end{array}$ & $\checkmark$ & \\
\hline $\begin{array}{l}\text { FO-thermal (hybrid of thermal distillation and forward } \\
\text { osmosis) }\end{array}$ & $\checkmark$ & $\checkmark$ \\
\hline Tight nanofiltration & $\checkmark$ & \\
\hline
\end{tabular}




\begin{tabular}{|l|c|c|}
\hline Desalination Technology & $\begin{array}{c}\text { Electric } \\
\text { Energy } \\
\text { Required }\end{array}$ & $\begin{array}{c}\text { Thermal } \\
\text { Energy } \\
\text { Required }\end{array}$ \\
\hline Loose nanofiltration & $\checkmark$ & \\
\hline Brackish-water reverse osmosis & $\checkmark$ & \\
\hline Seawater reverse osmosis & $\checkmark$ & \\
\hline $\begin{array}{l}\text { Dewvaporation, aka humidification-dehumidification } \\
\text { desalination }\end{array}$ & $\checkmark$ & \\
\hline Multi-effect humidification & $\checkmark$ & $\checkmark$ \\
\hline Mechanical vapor compression & $\checkmark$ & \\
\hline Thermal vapor compression & $\checkmark$ & $\checkmark$ \\
\hline Multi-stage flash & $\checkmark$ & $\checkmark$ \\
\hline Multi-effect distillation & $\checkmark$ & $\checkmark$ \\
\hline
\end{tabular}

\section{Beneficial-Use Criteria}

Several beneficial-use categories are included in GDsalt, which include potable use, livestock watering, crop irrigation, environmental restoration, and surface water discharge (see Appendix B). Two beneficial-use options were considered in the testing: potable use and crop irrigation. Target water-quality standards for the different beneficial-use categories are built into GDsalt. For drinking water, the U.S. Environmental Protection Agency (EPA) standards for drinking water quality are used [4]. The United Nations Food and Agriculture Organization water-quality criteria for irrigation were used for crop irrigation beneficial-use category [5].

\section{Impact of Contaminants}

GDsalt's source water database has a list of contaminants and constituents in a range of source waters (alternatively the user can input their own water quality data). Contaminants requiring removal are selected based on their concentration in the source water and target concentration levels required for the selected beneficial use. If the concentration of a constituent in the source water is above the limit or guideline required by the beneficial use, the contaminant is relevant in the selection of treatment methods. If the concentration of a constituent is above the limit required to protect membranes or other processes, a pretreatment process will be selected. The model outputs the list of constituents that require removal.

Protecting the treatment train from damage from source water constituents (e.g., fouling or mineral scaling) is required. Potential damage is partially a function of treatment efficiency, which is calculated using the Total Flux and Scalant methodology [6]. The methodology in GDsalt calculates the solubility index for both the source water and concentrate streams, and returns the ionic concentration and the scaling index of each stream. If the concentration of a constituent is above the limit required for protecting membranes or other processes from scaling, the contaminant is considered relevant in the selection of treatment methods, and GDsalt identifies pretreatment technologies necessary to protect membranes or heat exchanger surfaces before the source water flows to the desalination step.

\section{Expert Ranking Criteria}

The inclusion of a criteria ranking system allows the user to weight certain selection criteria and can be used to favor technologies that meet certain requirements - for example, compatibility 
with geothermal heat sources. The selection of a treatment train is based on the attributes of the treatment technologies with respect to a range of criteria such as rejection/removal capability of specific constituents by each process, ability to automate, operator skill level, flexibility, footprint, industrial status, chemical demand, energy demand, mobility, modularity, and relative capital cost. This is done by using a 5-point scale, where " 5 " indicates that the criterion is not favored and " 1 " indicates that the criterion is preferable. A criterion can be completely excluded if the user assigns a score of zero. This makes the tool more flexible by allowing the user to choose one or more criteria relevant to specific conditions.

\section{Treatment Efficiency}

Achieving the required treatment efficiency is a hard constraint. GDsalt will select a combination of most desirable technologies with respect to monetary and non-monetary criteria while achieving the target water-quality requirements for the selected beneficial use. Treatment efficiency, $R$, is defined as the percent rejection or removal of a specific constituent:

\section{User Preference}

$$
R=\left(\frac{C_{\text {feed }}-C_{\text {product }}}{C_{\text {feed }}}\right) * 100 \%
$$

GDsalt allows users to include or exclude treatment technologies from consideration, depending on their specific situation. The tool selects a combination of suitable treatment technologies with respect to technical and economic criteria; however, users may want to include or exclude specific treatment technologies.

\section{Pretreatment}

Pretreatment is carried out before desalination to protect elements of the desalination process, such as RO membranes [6]. This constraint is particularly important for some metals such as arsenic, barium, calcium, magnesium, and silica that may precipitate and cause crystallization and scaling. Removal of suspended solids is another common pretreatment requirement.

\section{GDsalt Output}

The primary output from GDsalt is one or more treatment train(s) that meet the treatment goals. In addition, GDsalt outputs the list of contaminants requiring removal, capital cost, annual O\&M cost, and electrical and thermal energy requirements. Although the treatment trains are listed in ranked order based on their composite score, it should be noted that some choices may not be significantly different from the other choices within the level of fidelity provided by the GDsalt analysis. The listed trains should be considered suitable options by the user, and user experience can be used to down-select from within the provided candidates.

\subsection{Testing GDsalt}

Organized testing of the GDsalt decision support tool was undertaken by a senior design class within the chemical engineering department at CSM. The class consisted of several teams composed of five seniors. The NREL team drafted a geothermal-desalination case study (see Appendix D) that was presented to the class as an analysis option. Five teams selected this case study for their project. The student groups were presented a series of source waters (Table 3) that required desalination prior to beneficial use of the water. The student groups were asked to 
design two separate treatment trains for two potential beneficial uses: potable reuse and crop irrigation. The water-quality requirements for the two beneficial uses are included in Table 4 . They used GDsalt to choose a treatment train for their chosen source waters, comparing the resulting treatment trains for each of the beneficial-use applications. Following this application of the tool, the student groups were asked to suggest improvements or adjustments to the tool based on their experience with its use. 
Table 3. Water chemistry of potential source waters

\begin{tabular}{|c|c|c|c|c|c|c|}
\hline & & $\begin{array}{r}\text { CA Salton } \\
\text { Sea surface } \\
\text { water } \\
\end{array}$ & $\begin{array}{r}\text { CA } \\
\text { New River } \\
\text { surface water }\end{array}$ & $\begin{array}{r}\text { TX Hidalgo } \\
\text { County } \\
\text { groundwater }\end{array}$ & $\begin{array}{r}\text { TX Gulf } \\
\text { coast } \\
\text { seawater }\end{array}$ & $\begin{array}{r}\text { TX Hidalgo } \\
\text { County } \\
\text { produced } \\
\text { water } \\
\end{array}$ \\
\hline Constituent List & Unit & & & & & \\
\hline Alkalinity-Bicarbonate & $\mathrm{mg} / \mathrm{L}$ & 245.0 & 300.0 & 563.8 & 171.0 & 77.6 \\
\hline Alkalinity-Carbonate & $\mathrm{mg} / \mathrm{L}$ & 2.0 & & - & 3.0 & - \\
\hline Ammonia & $\mathrm{mg} / \mathrm{L}$ & 1.2 & 3.6 & - & - & - \\
\hline Barium & $\mathrm{mg} / \mathrm{L}$ & - & & - & 0.1 & 4.0 \\
\hline Boron & $\mathrm{mg} / \mathrm{L}$ & 11.1 & 0.9 & - & 7.8 & - \\
\hline Calcium & $\mathrm{mg} / \mathrm{L}$ & 944.0 & 177.0 & 113.0 & 386.0 & $3,602.5$ \\
\hline Chloride & $\mathrm{mg} / \mathrm{L}$ & $17,240.0$ & 724.0 & $1,860.0$ & $17,083.0$ & $14,467.5$ \\
\hline Fluoride & $\mathrm{mg} / \mathrm{L}$ & 2.1 & 1.8 & 3.5 & - & - \\
\hline Iron (II) & $\mathrm{mg} / \mathrm{L}$ & - & & - & 4.7 & 261.7 \\
\hline Magnesium & $\mathrm{mg} / \mathrm{L}$ & $1,400.0$ & 82.8 & 105.0 & $1,135.0$ & 83.0 \\
\hline Nitrate (as N) & $\mathrm{mg} / \mathrm{L}$ & - & & 5.6 & - & - \\
\hline o-Phosphate & $\mathrm{mg} / \mathrm{L}$ & 0.0 & 0.7 & - & - & - \\
\hline $\mathrm{pH}$ & $\mathrm{pH}$ & - & & 7.9 & - & - \\
\hline Potassium & $\mathrm{mg} / \mathrm{L}$ & 258.0 & 12.6 & 26.4 & 487.0 & 244.6 \\
\hline Silica $\left(\mathrm{SiO}_{2}\right)$ & $\mathrm{mg} / \mathrm{L}$ & 4.6 & 7.3 & 60.1 & 24.0 & - \\
\hline Silver & $\mathrm{mg} / \mathrm{L}$ & - & & - & - & - \\
\hline Sodium & SAR & $12,368.0$ & 566.0 & $1,580.0$ & $8,468.0$ & $5,005.9$ \\
\hline Specific Conductance & $\mathrm{mg} / \mathrm{L}$ & - & & $5,901.0$ & - & - \\
\hline Strontium & $\mathrm{mg} / \mathrm{L}$ & 22.0 & 3.2 & - & 5.7 & - \\
\hline Strontium-90 & $\mathrm{mg} / \mathrm{L}$ & - & & - & - & - \\
\hline Sulfate & $\mathrm{mg} / \mathrm{L}$ & $10,500.0$ & 716.0 & $1,320.0$ & $2,642.0$ & 77.8 \\
\hline TDS (calc) & $\mathrm{mg} / \mathrm{L}$ & 44,087 & 2,440 & 5,359 & 30,515 & 23,591 \\
\hline Temperature & $\operatorname{deg} \mathrm{C}$ & 14 to 36 & 12 to 30 & 20.0 & 14 to 30 & 40.0 \\
\hline Total Nitrogen (as N) & $\mathrm{mg} / \mathrm{L}$ & - & 4.7 & - & - & - \\
\hline $\begin{array}{l}\text { Total Suspended } \\
\text { Solids (TSS) }\end{array}$ & $\mathrm{mg} / \mathrm{L}$ & 36.6 & 210.0 & 40.0 & & 40.0 \\
\hline Turbidity & NTU & - & & - & 5.0 & - \\
\hline
\end{tabular}


Table 4. Water-quality requirements for selected beneficial uses

\begin{tabular}{|c|c|c|c|}
\hline Component & Units & Potable use & $\begin{array}{l}\text { Crop irrigation, } \\
\text { non-potable use }\end{array}$ \\
\hline Aluminum & $\mathrm{mg} / \mathrm{L}$ & 0.200 & 5.000 \\
\hline Ammonia & $\mathrm{mg} / \mathrm{L}$ & 0.000 & 0.000 \\
\hline Arsenic (III) & $\mathrm{mg} / \mathrm{L}$ & 0.010 & 0.100 \\
\hline Arsenic (V) & $\mathrm{mg} / \mathrm{L}$ & 0.010 & 0.100 \\
\hline Barium & $\mathrm{mg} / \mathrm{L}$ & 2.000 & - \\
\hline Benzene & $\mathrm{mg} / \mathrm{L}$ & 0.005 & - \\
\hline Beryllium & $\mathrm{mg} / \mathrm{L}$ & 0.004 & - \\
\hline Cadmium & $\mathrm{mg} / \mathrm{L}$ & 0.005 & - \\
\hline Chloride & $\mathrm{mg} / \mathrm{L}$ & 250.000 & 70.000 \\
\hline Chlorobenzene & $\mathrm{mg} / \mathrm{L}$ & 0.100 & - \\
\hline Chromium, total & $\mathrm{mg} / \mathrm{L}$ & 0.100 & 0.100 \\
\hline Copper & $\mathrm{mg} / \mathrm{L}$ & 1.300 & 1.300 \\
\hline Cyanide & $\mathrm{mg} / \mathrm{L}$ & 0.200 & - \\
\hline Ethylbenzene & $\mathrm{mg} / \mathrm{L}$ & 0.700 & - \\
\hline Ethylene Dibromide & $\mathrm{mg} / \mathrm{L}$ & 0.000 & - \\
\hline Fluoride & $\mathrm{mg} / \mathrm{L}$ & 2.000 & 1.000 \\
\hline Iron (II) & $\mathrm{mg} / \mathrm{L}$ & 0.300 & 5.000 \\
\hline Iron (III) & $\mathrm{mg} / \mathrm{L}$ & 0.300 & 5.000 \\
\hline Lead & $\mathrm{mg} / \mathrm{L}$ & 0.015 & 5.000 \\
\hline Lithium & $\mathrm{mg} / \mathrm{L}$ & - & 15.000 \\
\hline Manganese & $\mathrm{mg} / \mathrm{L}$ & 0.050 & 0.200 \\
\hline Mercury & $\mathrm{mg} / \mathrm{L}$ & 0.002 & - \\
\hline Nickel & $\mathrm{mg} / \mathrm{L}$ & - & 0.200 \\
\hline Nitrate (as N) & $\mathrm{mg} / \mathrm{L}$ & 10.000 & 10.000 \\
\hline Nitrite (as N) & $\mathrm{mg} / \mathrm{L}$ & 1.000 & 1.000 \\
\hline Radioactivity, Gross Beta & $\mathrm{pCi} / \mathrm{L}$ & 15.000 & - \\
\hline Radium-226 + Radium-228 & $\mathrm{pCi} / \mathrm{L}$ & 4.000 & - \\
\hline $\operatorname{Rd} 226+222+228$ & $\mathrm{pCi} / \mathrm{L}$ & 5.000 & - \\
\hline Selenate & $\mathrm{mg} / \mathrm{L}$ & 0.050 & 0.020 \\
\hline Silver & $\mathrm{mg} / \mathrm{L}$ & 0.100 & - \\
\hline TDS (calc) & $\mathrm{mg} / \mathrm{L}$ & 500.000 & 1500.000 \\
\hline Thallium, total & $\mathrm{mg} / \mathrm{L}$ & 0.002 & - \\
\hline Total Suspended Solids (TSS) & $\mathrm{mg} / \mathrm{L}$ & 30.000 & 30.000 \\
\hline Uranium & $\mu \mathrm{g} / \mathrm{L}$ & 30.000 & - \\
\hline Xylenes (total) & $\mathrm{mg} / \mathrm{L}$ & 10.000 & - \\
\hline Zinc & $\mathrm{mg} / \mathrm{L}$ & 5.000 & - \\
\hline
\end{tabular}

After the test runs of GDsalt were completed, each group provided suggestions or changes to the GDsalt program in order to increase the usability. The suggested changes fell within the following categories:

- Data input, 
- Transparency of background calculations and results,

- Energy cost estimations of thermal distillation technologies,

- Improvements to the GUI, and

- Errors and questions encountered during the runs.

Several groups faced difficulties relating to the tool reverting to default settings upon closing the program. This default caused problems for comparing results, increased the time for using the program through redundancy, and increased the possibility of error. The recommendation was made to save the initial inputs after each test and restore default values to the interface only when the user selects this option. Another suggestion was a two-way GUI that shows the currently set values for each section, or an input sheet that includes the data as they were input by the user.

Another difficulty faced in the program was the lack of clarity in the calculations and default values, as well as in the results of the GDsalt runs. Background calculations were difficult to find by the user, and the detailed results section of the program was confusing and difficult to navigate. The groups suggested more detailed labeling and documentation of the background calculations, variables, and constants, as well as a more clearly defined results section that goes beyond the current initial summary table.

The groups encountered many issues regarding the energy use and cost calculations within the program. These issues included the inability of the program to differentiate between increasing percent recoveries, and the overestimation of required energy and the cost of this energy.

Because the energy used in these processes largely determines the O\&M costs, it is imperative to have accurate cost estimations to ensure correct selection of the treatment trains. Furthermore, the capital costs were perceived to be underestimated due to the exclusion of some heat-transfer equipment. The suggestion was made that multiple energy-cost levels in economic inputs (i.e., one unit cost for the geothermal energy input and another for any additional heat energy required) would allow for more accurate cost estimations, especially in the case of an energy deficit. Again, the groups asked for more clarity in the cost calculations and economic inputs in order to simplify later cost calculations.

Several suggestions centered on the GDsalt GUI. Multiple groups suggested integrating the beneficial-use selection into the initial user inputs, rather than being a pop-up selection that the user must select after the program is already running. One group suggested the addition of an output tab to the GUI that would allow the user to copy the run results to another workbook. This option would be very helpful, especially if the output option included the initial user inputs, and would allow for a more comprehensive comparison of results. Increasing the size of the user preferences window would decrease or eliminate the need to scroll through the lists, making the program easier to use. For the geothermal input, it would be beneficial to add an option for steam. Finally, there were many suggestions on the inclusion/exclusion of treatment processes. One team suggested that the inclusion and exclusion lists should be merged, while also adding checkboxes, with "select all" checkboxes for the subsections of pretreatment, desalination, and post-treatment.

Two teams encountered errors while using the program. The teams stated that the program would not allow them to include a specific desalination technique in the selection process, and they 
were forced to exclude every process except the one desired desalination technique. The second team was given an error while GDsalt was running saying that it had to be re-run. When the team clicked "okay," the program began a non-stop loop-encountering the error, but not allowing the user to escape back to the home screen to fix the error. In this case, the team had to restart the program. Therefore, an option to cancel a program run was recommended.

Finally, one team struggled with understanding why there was no difference in some process trains and requested more analysis detail on removal rates of contaminants in order to understand GDsalt's selections. They also asked for the option to rank selections based on the individual user input scores rather than the overall process score. Such information is beyond what could be provided within GDsalt, but may be appropriate for a user manual.

The engineers at NREL and CSM's Advanced Water Technology Center reviewed the results of this testing, as well as the suggestions for improvement for the GDsalt program. The revised form of GDsalt is available for users, in addition to an updated user manual for the tool. The spreadsheet tool and manual can be obtained at the AQWATEC website at http://aqwatec.mines.edu/research/GT_Desal/ 


\section{Desalination Technologies}

\subsection{Thermal Technology Options and Effect of Plant Capacity}

Desalination is a multibillion dollar, worldwide industry. As such, there have been numerous assessments of desalination technologies and costs. Representative costs for desalinated water is presented in Figure 5 [7]. Multistage flash (MSF), multi-effect distillation (MED), and reverse osmosis (RO) are the top three desalination technologies in terms of worldwide installed capacity [7]. RO is an all-electric technology, whereas MSF and MED are primarily thermal, with some electric demand for pumping and controls. RO is the leading desalination technology worldwide and is typically the lowest-cost option for seawater desalination.

For geothermal desalination designs, one could employ the geothermal source for electric power production and couple that power source with an RO system. However, electricity generation with a low-temperature geothermal resource is very inefficient, so direct use of the geothermal heat is preferred. Examining the thermal desalination processes in Figure 5, one notes that the dominant cost categories are the capital equipment and the cost for thermal energy. Thus, the ideal technology for geothermal desalination would be a thermal technology with a low capital cost, especially at small scale. Thermal energy consumption is a lesser concern, assuming one can tap into a low-cost geothermal heat source.

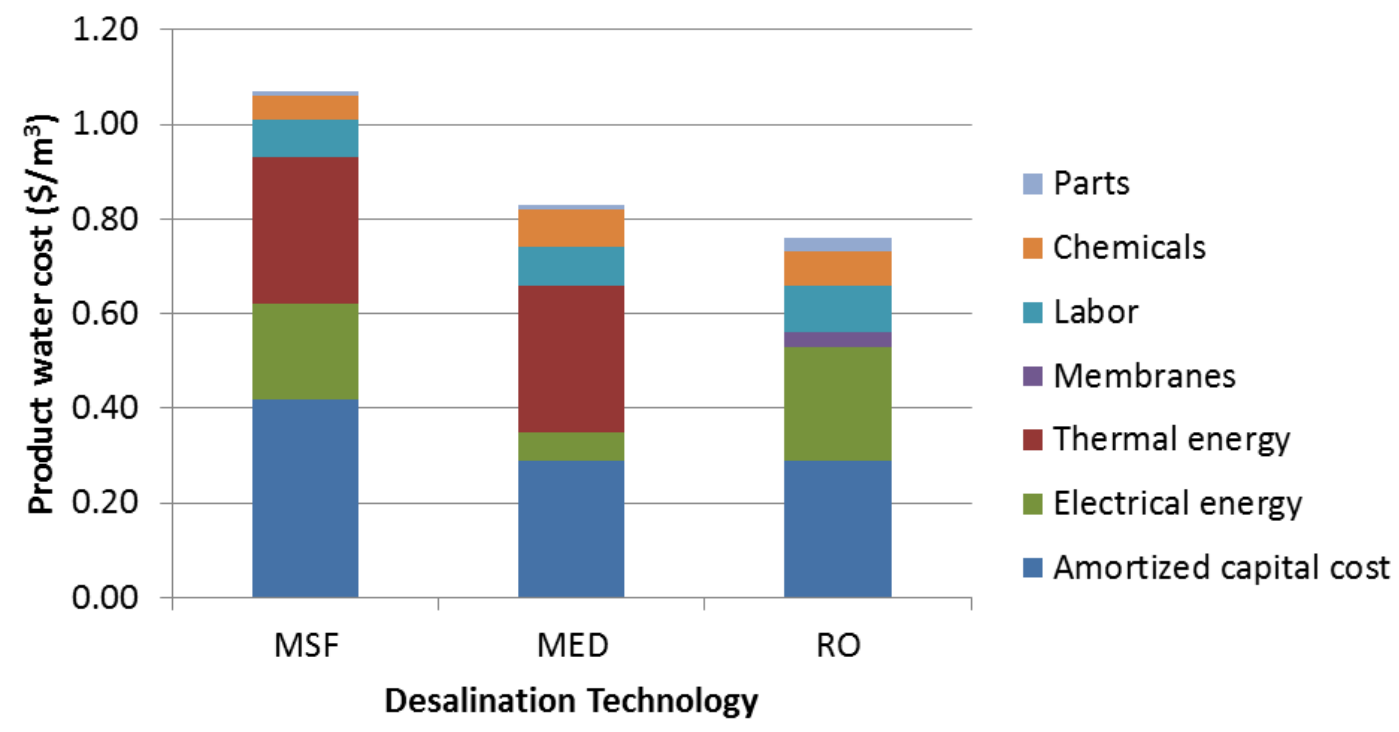

Figure 5. Distribution of cost by category for common desalination technologies [7]. Values are based on a large seawater desalination plant.

As with many technologies, the cost of the product varies with plant size, although the different technologies exhibit different sensitivity to scale. Kesieme and coworkers [8] highlight the variation in product-water cost with plant size, as shown in Figure 6 . The greatest cost reductions occur when one moves from small plant capacities (less than $1,000 \mathrm{~m}^{3} /$ day) to a few thousand cubic meters per day. The cost of membrane-based systems, such as RO and membrane distillation (MD), is less sensitive to plant capacity due to the modular nature of these technologies. 


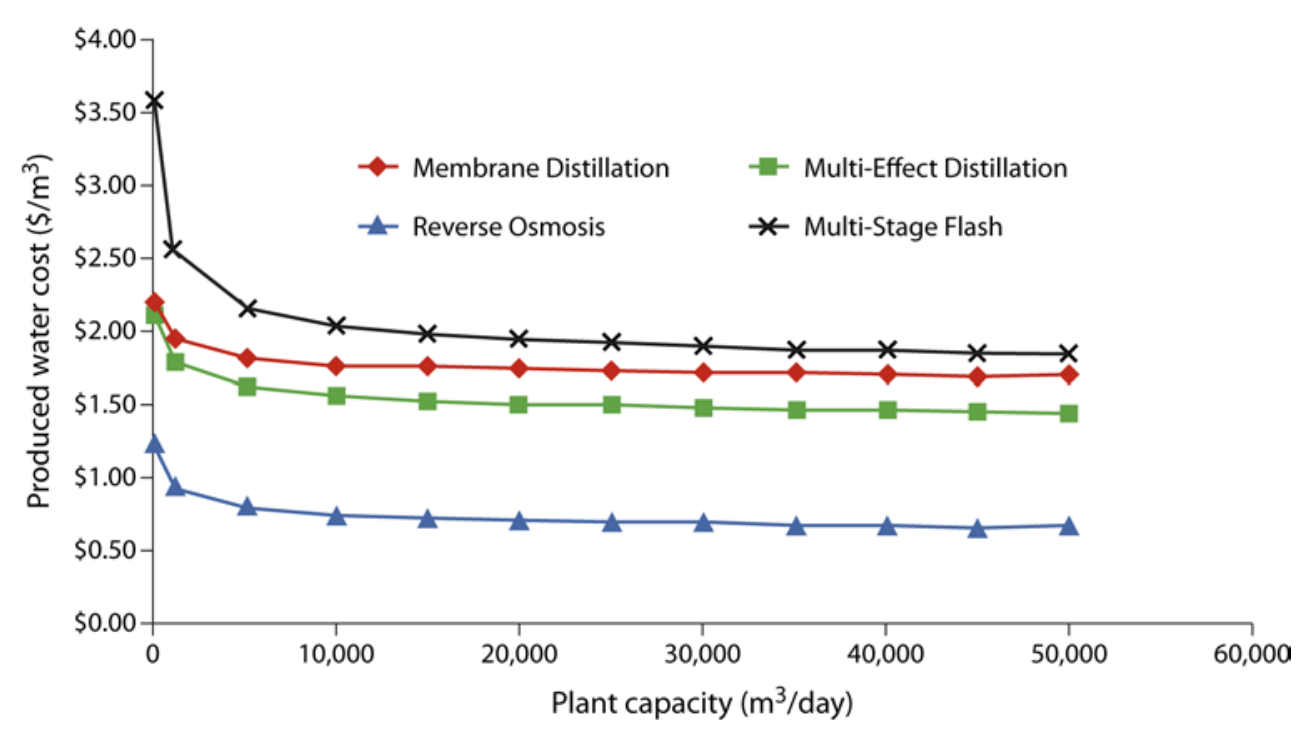

Figure 6. Modular RO and MD desalination technologies are less sensitive to economies of scale than MSF and MED [8]. This makes RO and MD technologies a better match for small plant sizes.

Geothermal desalination systems are expected to be relatively small-capacity units

Assuming a $40^{\circ} \mathrm{C}$ temperature differential and a geothermal well flowing at $4 \mathrm{~m}^{3} / \mathrm{min}(1,080$ gpm), the available geothermal energy is about $11.2 \mathrm{MW}_{\text {th }}$ or $270 \mathrm{MWh}_{\text {th }}$ per day. Thermal desalination processes are governed by the latent heat of vaporization of water, which is about $2,270 \mathrm{~kJ} / \mathrm{kg}\left(630 \mathrm{kWh} / \mathrm{m}^{3}\right)$; thus, in the absence of energy recovery, the maximum water production from such a geothermal source is about $426 \mathrm{~m}^{3} /$ day:

$$
\begin{gathered}
Q_{\text {geo }}=\dot{m}_{\text {brine }} C p \Delta T=(4000 \mathrm{~kg} / \mathrm{min}) *(4.2 \mathrm{~kJ} / \mathrm{kg}-\mathrm{K}) *(40 \mathrm{~K})=672,000 \mathrm{~kJ} / \mathrm{min}=11,200 \mathrm{~kW} \text { th } \\
\dot{m}_{\text {water }}=Q_{\text {geo }} / \Delta H_{\text {vap }}=(672,000 \mathrm{~kJ} / \mathrm{min}) /(2270 \mathrm{~kJ} / \mathrm{kg})=296 \mathrm{~kg} / \mathrm{min}=426 \mathrm{~m}^{3} / \text { day }
\end{gathered}
$$

A common figure of merit, the gained-output ratio (GOR), is defined as the mass of water produced per mass of steam fed to the process, where the mass of steam is a surrogate for the latent heat of steam. Accordingly, in the calculations above, an energy demand of $630 \mathrm{kWh} / \mathrm{th} / \mathrm{m}^{3}$ represents $G O R=1$. Heat recovery is applied in thermal desalination systems to improve thermal efficiency, albeit at greater hardware cost. Multiple stages or effects are added to recover the heat of vaporization by preheating the next effect. Optimizing the number of effects is a tradeoff between initial capital cost and complexity versus energy use and operating cost. Typical GOR values for commercial MED systems range from 6-10 [9]. Even at GOR = 10, the daily production in our example case is only about $4,000 \mathrm{~m}^{3} /$ day. Clearly, desalination systems designed to take advantage of low-grade geothermal heat must be suitable for implementation at the relatively small scale of hundreds to a few thousand cubic meters per day.

\section{Best small-capacity thermal desalination choice}

The assumption that geothermal desalination facilities will be of modest capacity strengthens the rationale for selecting a modular technology such as MD for integration with the geothermal resource. Figure 7 compares the cost categories as a function of system capacity for two thermal desalination technologies-MED and MD. The advantage of MED shrinks as system capacity decreases. The MD technology cost is less sensitive to system capacity, but is more sensitive to 
thermal-energy cost than the MED technology. This suggests that MD will be favored as one moves toward small-capacity units and can take advantage of low-cost thermal-energy sources. In fact, Kesieme and coworkers highlighted this in their recent analysis. Figure 8 illustrates how the MD system becomes the lowest-cost technology — versus MED or RO-at low thermalenergy costs. Furthermore, the advantage of MD is greatest at the lowest plant capacities.

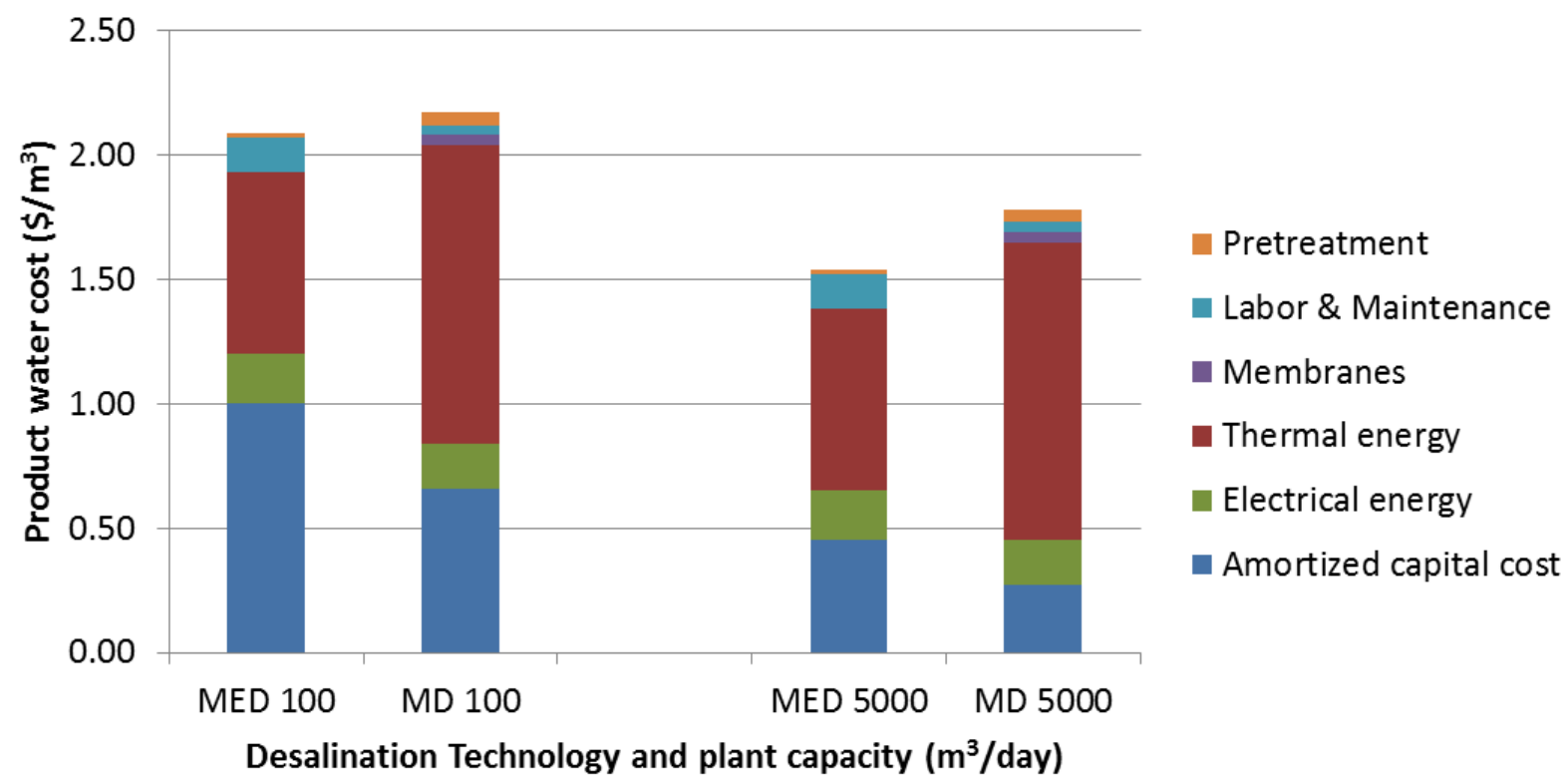

Figure 7. Comparison of two thermal desalination technologies: MED and MD. At either scale, MD exhibits a lower capital cost but greater thermal-energy consumption. Data from [8].

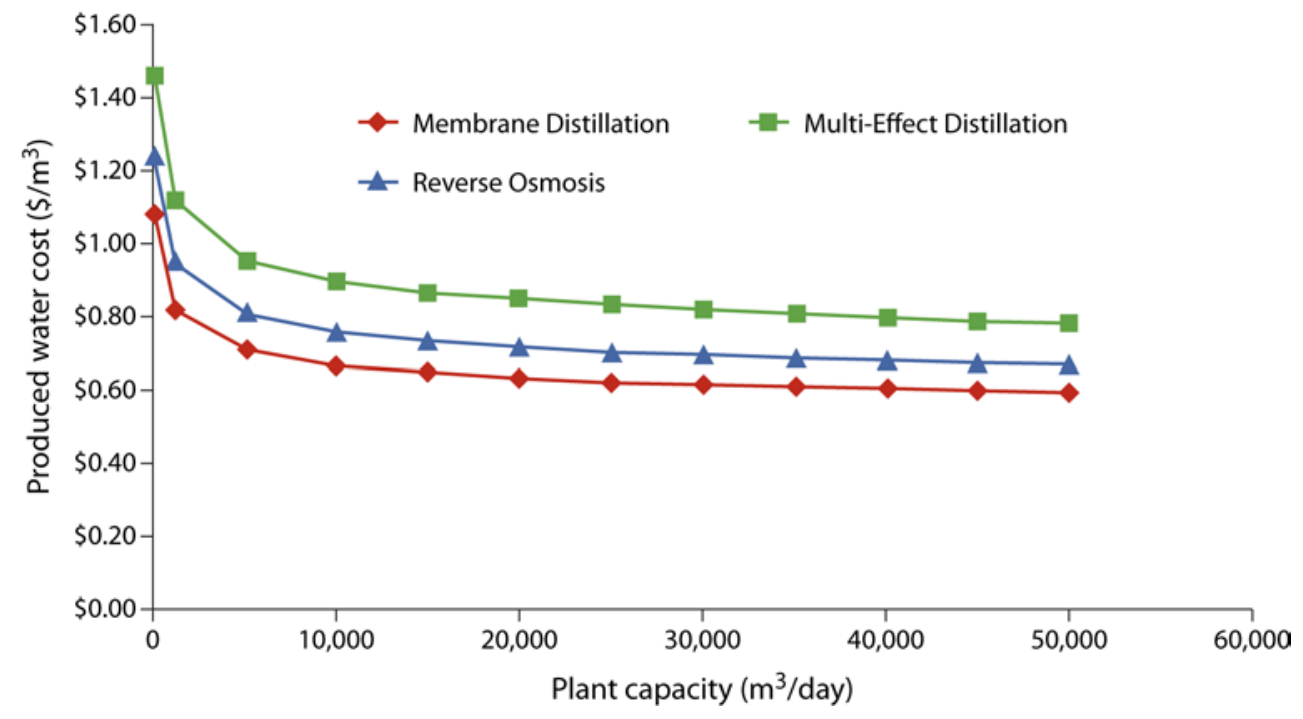

Figure 8. The combination of modularity and reliance on thermal energy means that MD systems can be the lowest-cost desalination option in small systems if low-cost thermal energy is available. This chart repeats the analysis shown in Figure 6, assuming a tenfold decrease in thermal-energy costs [8]. 
Walton et al. [10] also developed a cost estimate for MD as a function of thermal energy, assuming that the capital cost of the facility is the same as for seawater $\mathrm{RO}\left(\$ 0.375 / \mathrm{m}^{3}\right)$; they also compared it to RO, assuming the energy cost of RO accounted for $50 \%$ of the total water cost. Walton et al. concluded that MD is competitive relative to RO when low-cost heat energy is available and when the water chemistry of the source water is too difficult for treatment with RO.

\subsection{Membrane Distillation: A Good Match for Geothermal}

Membrane distillation was originally proposed in the 1960s, but has only recently been the subject of commercial interest because the technology to produce thermally stable membranes has improved. MD offers several potential advantages, including that it:

- Produces superior product water-quality compared to RO. High-purity product water is a general characteristic of thermal desalination technologies. Although this can be valuable in some applications (e.g., producing boiler feedwater), some mineral content needs to be added for potable use;

- Can treat higher-salinity brines than RO;

- Uses low-grade heat for its primary energy input $\left(<100^{\circ} \mathrm{C}\right)$;

- Accommodates sensible (e.g., hot water) heat input;

- Operates at near-ambient pressure;

- Uses lower-cost membranes due to pressure and temperature conditions that allow use of inexpensive plastics (e.g., PVDF, polypropylene) as construction material and a pore size that is orders-of-magnitude larger than required for RO membranes;

- Provides a modular design that is amenable to small-scale facilities; and

- Can tolerate variable operating conditions, including stop/start cycles.

It should be noted that although MD filters are simpler than RO membranes, production volume of MD membranes is, at present, much lower than RO membranes, thus negating the potential cost advantage at this time.

The basic components of an MD system are depicted in Figure 9. The MD process uses hydrophobic, microporous membranes and the driving force is the partial vapor-pressure difference across the membrane. There are various implementations of the basic MD technology to improve efficiency - for example, air-gap MD and sweep-gas MD — but they share the attributes listed above. Camacho [11] states that MD has thermal-energy requirements ranging from 120 to $1,700 \mathrm{kWh} / \mathrm{m}^{3}$ (GOR $=0.4$ to 5.2$)$ depending on conditions and design. Data given from two MD developers, Aquastill and Memsys, list thermal-energy demands of 56 to 350 $\mathrm{kWh}_{\mathrm{th}} / \mathrm{m}^{3}(\mathrm{GOR}=1.8$ to 11$)[11]$. 


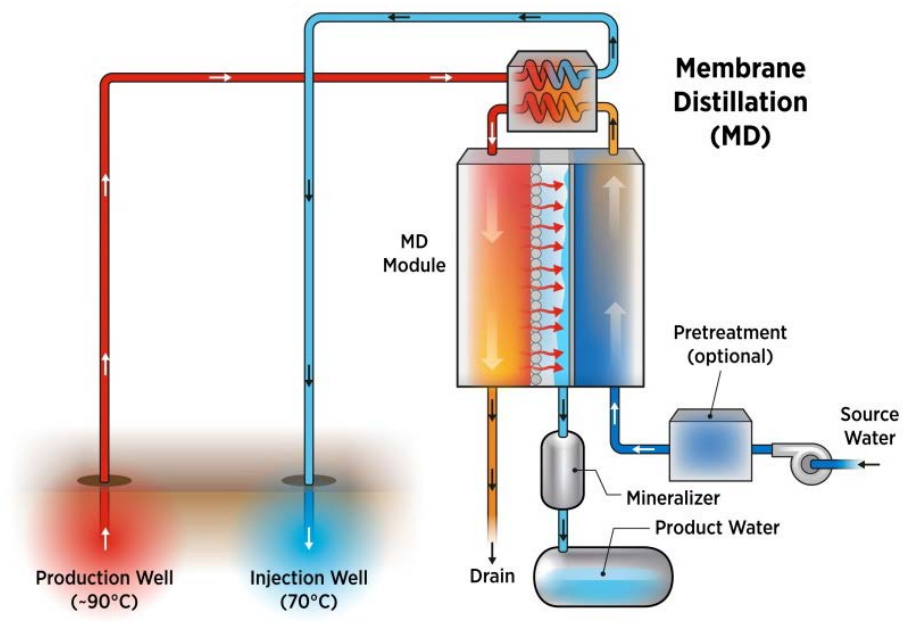

Figure 9. Basic MD system with a hot source water. Water vapor passes through the membrane from the hot-brine side to the cool-permeate side.

The simplest form of MD is direct-contact membrane distillation (DCMD), as illustrated in Figure 10a. DCMD is favored in many trials due to its simplicity; however, thermal conduction across the membrane makes this the least-efficient form. In air-gap MD (AGMD, Figure 10b), the air gap is usually the controlling factor for the mass and heat transfer because of its greater thermal and mass-transfer resistances. In comparison with the thickness $(40-250 \mu \mathrm{m})$ and conductivity of the membrane, the air gap is much thicker $(2,000-10,000 \mu \mathrm{m})$ and has lower thermal conductivity [11]. Therefore, more thermal energy in AGMD will be used for water evaporation than in DCMD. Additionally, if a low-temperature feed is used as the cooling stream in this configuration, the latent heat can be recovered through the condensation of the vapor on the cooling plate. However, AGMD typically has a low flux, due to the low temperature difference across the membrane, and therefore, larger surface areas are required.

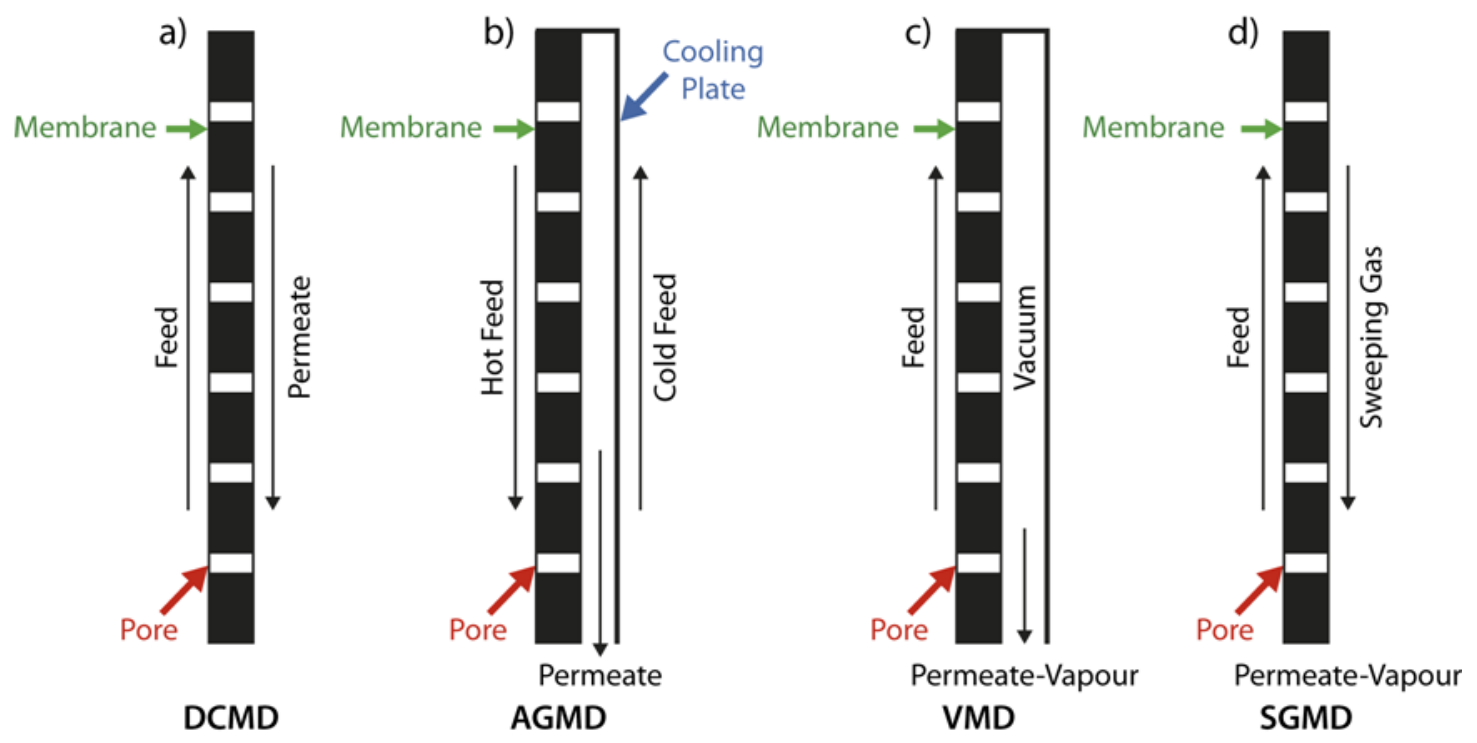

Figure 10. Basic types of membrane distillation: (a) direct-contact MD, (b) air-gap MD, (c) vacuum MD, and (d) sweep-gas MD [11]. 
Vacuum MD and sweep-gas MD endeavor to increase thermal efficiency and/or flux, but require more hardware, which somewhat negates MD's advantage of simplicity. AGMD has been deployed by one developer (Dutch developer Aquastill), and vacuum MD is being promoted by Aquastill and the German company Memsys $\mathrm{GmbH}$, which recently partnered with GE to explore the treatment of produced water from the oil and gas industry (http://www.memsys.eu/). The Memsys/GE partnership is targeting MD treatment of water that is challenging for other desalination technologies (see Figure 11).

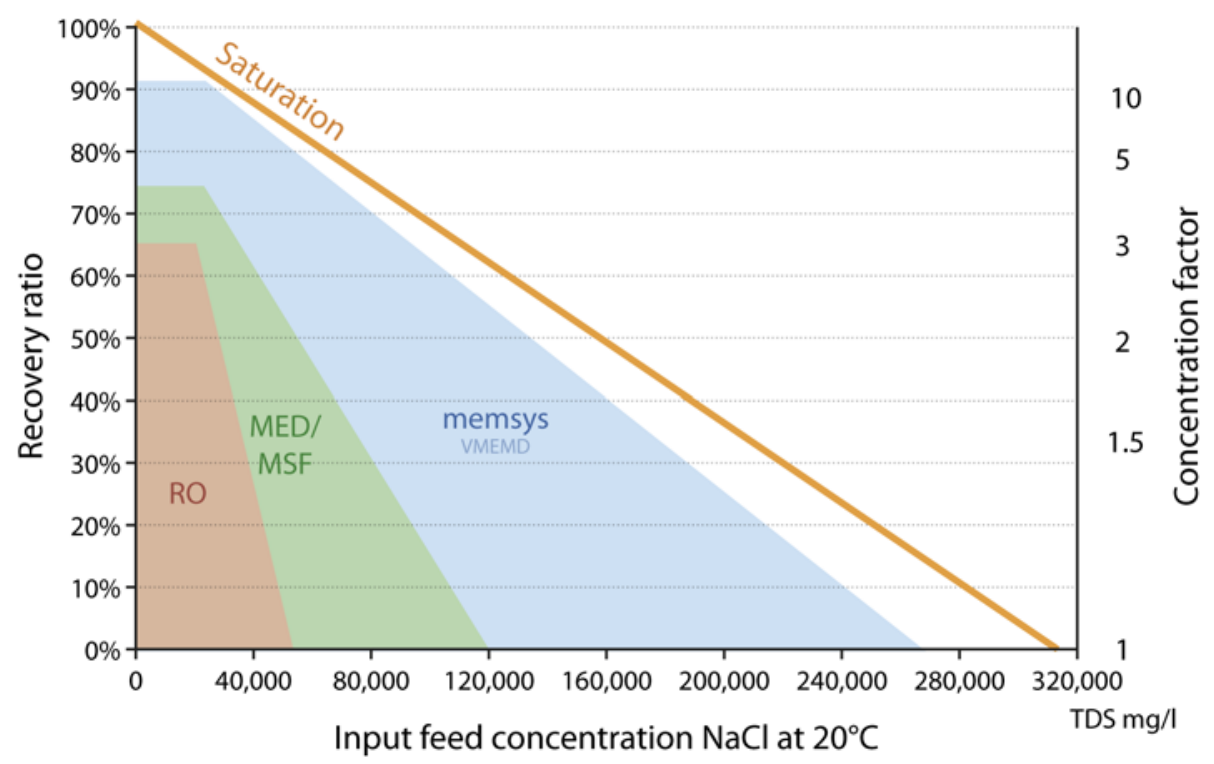

Figure 11. Plot of recovery ratio vs. TDS, showing regions of applicability of different desalination technologies [12]. MD systems can achieve recovery fractions and handle high-TDS waters that RO cannot. The arrows show hypothetical treatment strategies.

\subsection{Membrane Distillation: Costs and Opportunities}

Camacho's [11] review of the literature indicates than MD can produce high-purity water from poor-quality source water at a cost in the range of $\$ 1.2 / \mathrm{m}^{3}$, which could be lowered to less than $\$ 0.5 / \mathrm{m}^{3}$ if low-cost heat is available. Realizing Camacho's lower bound will require taking advantage of the potential capital-cost savings of the emerging MD technology, as well as providing low-cost thermal energy - for example, from low-enthalpy geothermal sources such as unused wells or reinjection brine.

Al-Obaidani et al. [13] performed an MD cost analysis based on a combined membrane/element cost of $\$ 90 / \mathrm{m}^{2}$. There are no dedicated MD membranes on the market, but classical microfiltration membranes that are used in commercial MD units exhibit good fluxes and selectivity. Since 2008, the market for ultra/microfiltration membranes has grown and costs have decreased. The most recent in-house economic models of CSM use a microfiltration membrane and element cost of $\$ 14 / \mathrm{m}^{2}$ and $\$ 24 / \mathrm{m}^{2}$, respectively. The combined cost of $\$ 38 / \mathrm{m}^{2}$ is less than half the cost assumed by Al-Obaidani in 2008. Given that Al-Obaidani reported that membrane/element costs account for about $50 \%$ of the total cost, this represents an approximate $25 \%$ drop in capital cost for the MD system over the past seven years.

Kesieme et al. [8] identified scenarios where MD could be competitive with state-of-the-art desalination technologies, such as RO or MED. Compared to MED, MD is predicted to have 
lower capital cost, but higher thermal-energy requirements (see Figure 12). The cost divisions indicate that low-cost thermal energy, for example, from a geothermal source, will have a more pronounced impact on MD costs than on the cost of MED.
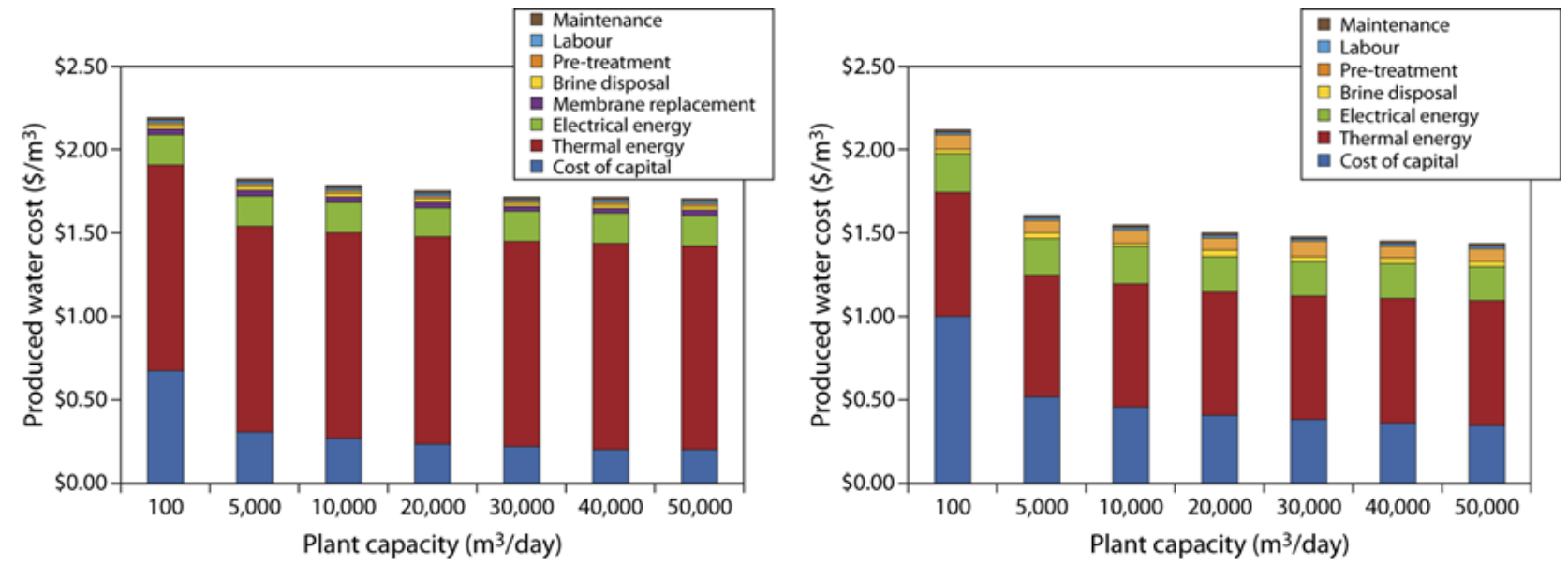

Figure 12. Water cost by cost category for MD (left) and MED (right) systems [8]. For MD, overall cost is dominated by the cost of thermal energy.

Furthermore, from Kesieme's calculations, one can determine the cost of thermal energy that brings MD in line with a target cost of about $\$ 1 / \mathrm{m}^{3}$. Kesieme assumed the cost of thermal energy from steam generated in a natural gas boiler was $\$ 0.0124 / \mathrm{kWh}_{\text {th }}(\$ 3.6 / \mathrm{MMBtu})$. Examining the $5,000 \mathrm{~m}^{3} /$ day bar in Figure 12, we note that if thermal-energy costs are reduced by $66 \%$, the estimated MD cost for product water drops to about $\$ 1 / \mathrm{m}^{3}$. (The value drops to about $\$ 1.4 / \mathrm{m}^{3}$ at the $100 \mathrm{~m}^{3} /$ day capacity.) This cost, $\$ 0.0041 / \mathrm{kWh}_{\text {th }}$ or $\sim \$ 1.2 / \mathrm{MMBtu}$, is compared to the cost of heat generated from potential geothermal sources in Section 5.2.

In Kesieme's analysis (Figure 12), MED is lower cost than MD at all except the smallest plant sizes. However, if low-cost thermal energy is available, the cost advantage shifts toward MD. As with RO, MD retains an advantage over MED in that it is able to operate over a wider range of conditions. MD can operate at slightly higher concentrations versus MED because the temperature drops throughout the MD module, solubilizing common scalants such as $\mathrm{CaCO}_{3}$. More importantly, MD can operate at much lower temperatures than MED, enabling the use of much lower-value and more-abundant heat sources. The minimum feed temperature for MED is $70^{\circ} \mathrm{C}$, whereas there is technically no limit to the hot-side temperature of MD as long as the distillate temperature is lower [14].

Moreover, based on the assessment by NREL/CSM, Kesieme's assumed electrical consumption of $2 \mathrm{kWh} / \mathrm{m}^{3}$ for MD is conservative, which might further lower cost. For comparison, CSM has ordered two 27- $\mathrm{m}^{2} \mathrm{MD}$ modules from Aquastill in the Netherlands with a claimed electrical consumption of $0.313 \mathrm{kWh} / \mathrm{m}^{3}$. Recently, new MD configurations have been suggested with order-of-magnitude lower electrical consumption due to much higher water recoveries [15]. CSM is working closely with Aquastill to test the performance and scalability of these new modules. 


\subsection{Challenges for Membrane Distillation}

In MD processes, heat and mass transfer are coupled, and it is desired to minimize the former and maximize the latter. Water evaporates and is transported across the hydrophobic membrane, while heat is simultaneously conducted through the membrane from the feed stream to the product (distillate) stream. The driving force for mass transfer is the partial vapor-pressure difference across the membrane - that is, between $T_{1}$ and $T_{2}$ in Figure 13. Reducing the boundary layers on either side of the membrane is an important path to increasing mass transport. If this is accomplished (e.g., through the use of flow-turbulence enhancers and/or VMD or SGMD), the mass transport will be governed by diffusion through the membrane.

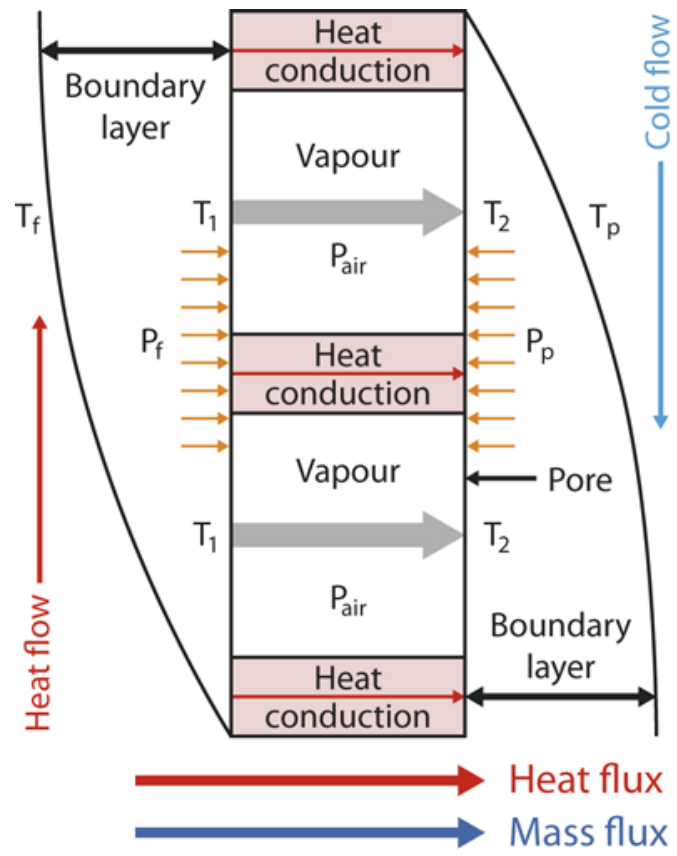

Figure 13. Heat and mass transfer across a membrane [11].

The most common materials used for MD membranes are polytetrafluoroethylene (PTFE), polypropylene (PP), and polyvinylidenefluoride (PVDF). The porosity of the membranes ranges from 0.60 to 0.95 , the pore size ranges from 0.2 to $0.5 \mu \mathrm{m}$, and the thickness ranges from 0.04 to $0.25 \mathrm{~mm}$ [11]. PTFE has the highest hydrophobicity, but also the highest thermal conductivity and cost. Membranes can be provided as sheets, spiral-wound modules, or hollow-core fibers. Good MD membranes must balance several factors:

- Thickness. Thinner membranes increase membrane permeability (which is good; better mass flux) and decrease thermal resistance (which is bad; lower thermal efficiency). Membranes must also be thick enough to provide mechanical strength.

- Reasonably large pore size and narrow pore-size distribution, limited by the minimum liquid entry pressure (LEP) of the membrane. In MD, the hydrostatic pressure must be lower than LEP to avoid membrane wetting.

- Low surface energy, equivalent to high hydrophobicity. Materials with higher hydrophobicity can be made into membranes with larger pore sizes, or membranes made 
from more hydrophobic material will be applicable under higher pressures for a given pore size.

- Low thermal conductivity to minimize heat transfer and reduce vapor flux due to reduced interface temperature difference.

- High porosity. High porosity decreases thermal transfer and increases mass transfer, so both the heat efficiency and mass flux are increased. However, high-porosity membranes have low mechanical strength and tend to crack or compress under mild pressure, which results in the loss of membrane performance.

Membrane fouling is a major obstacle in the application of all membrane technologies, because it causes flux to decline. The foulant (e.g., bio-film, precipitations of organic and inorganic matter) can reduce the permeability of a membrane by clogging the membrane surface and/or pores. Dow et al. [16] showed that lower feed temperatures typical of MD can substantially reduce the influence of fouling in direct-contact MD. Scale formation is traditionally managed in water systems by use of anti-scalants.

Because the hydrophobic MD membrane is the barrier between the feed and permeate, membrane wetting will reduce the rejection of the non-volatiles and degrade product-water quality. Membrane wetting can occur under the following conditions [11]:

- The hydraulic pressure applied on the surface of the membrane is too high,

- A foulant depositing on the membrane surface can effectively reduce the hydrophobicity of the membrane,

- Organic materials or surfactants in the source water can adsorb to the membrane and reduce the hydrophobicity of the membrane, or

- Organic materials or surfactants in the source water can lower the surface tension of feed solution.

MD is driven by partial vapor-pressure difference, which varies exponentially with the stream temperature; thus, the flux is affected greatly by the feed temperature. Furthermore, because the heat loss through thermal conduction varies only linearly with temperature difference across the membrane, the proportion of energy used for evaporation will increase as the feed temperature increases. Although MD systems can operate at lower temperatures than other thermal desalination processes, the benefits of greater flux generally influences one to operate at the highest temperature that the membrane and heat source allow. 


\section{Low-Temperature Geothermal Resources}

\subsection{Prevalence}

As reported by the U.S. Geological Survey, most of the identified low-temperature geothermal systems are hydrothermal convection systems, which can be subdivided into isolated systems and delineated-area systems [17]. Isolated systems are hydrothermal reservoirs with surface evidences and thermal springs, or a well that produces thermal water. They have geologic control and commonly occur along normal faults or folded and thrusted rocks. Delineated-area systems are characterized by the upflow of thermal water along faults and its subsequent lateral movement into aquifers at relatively shallow depths. There may not be an associated discharge of thermal springs at the surface, and the shallow thermal aquifer may be underlain by a hotter reservoir at greater depths. The beneficial heat available from the low-temperature resource can be calculated as a fixed fraction of the wellhead thermal energy using the empirical equation given below [17]:

where:

$$
q_{\text {ben }}=0.6 \rho C\left(\frac{k a}{a_{w}}\right) \cdot Q \cdot P \cdot\left(T_{r}-25\right)
$$

$\begin{array}{ll}q_{\text {ben }} & \text { Beneficial heat }\left(\mathrm{MW}_{\text {th }}\right) \\ Q & \text { Volumetric flow } \\ \rho C & \text { Volumetric specific heat }\left(\mathrm{J} / \mathrm{cm}^{3}-\mathrm{K}\right) \\ k & \text { Transmissivity constant }(\text { values between } 0 \text { and } 1) \\ a & \text { Reservoir area }\left(\mathrm{km}^{2}\right) \\ a_{w} & \text { Optimum reservoir area per well }\left(\mathrm{km}^{2}\right) \\ P & \text { Duration of production period } \\ \left(T_{r}-25^{\circ} \mathrm{C}\right) & \text { Usable temperature dropdown }\left({ }^{\circ} \mathrm{C}\right) \\ \left(\mathrm{ka} / \mathrm{a}_{w}\right) & \text { Mean number of wells each reservoir can support according to the }\end{array}$

The units for reporting beneficial heat are megawatts thermal ( $\left.\mathrm{MW}_{\text {th }}\right)$ for 30 years, and the values obtained represent energy that might actually be used in applications at the surface. Mean resource energy for each identified thermal reservoir is calculated either by assuming a $25 \%$ recovery factor for those reservoirs with a standard volume of $1 \mathrm{~km}^{3}$, or by estimating the number of production wells that a reservoir with a larger-than-standard volume can support for 30 years with a cumulative drawdown of $152 \mathrm{~m}$ [17]. Table 5 lists the total estimated resource capacity for identified isolated systems and delineated geothermal systems having mean reservoir temperature between $50^{\circ} \mathrm{C}$ and $90^{\circ} \mathrm{C}$. It should be noted that the USGS is currently updating the 1982 assessment of low-temperature geothermal resources [18]. 
Table 5. Distribution of geothermal beneficial heat and mean resource energy by state for hydrothermal convectional systems having mean reservoir temperature between $50^{\circ} \mathrm{C}$ and $90^{\circ} \mathrm{C}$ (Original data source is [17])

\begin{tabular}{|c|c|c|c|c|c|c|c|}
\hline \multirow[b]{3}{*}{ States } & \multicolumn{7}{|c|}{ Hydrothermal-Convectional* } \\
\hline & \multicolumn{3}{|c|}{ Isolated Systems } & \multicolumn{3}{|c|}{ Delineated Systems } & \multirow[b]{2}{*}{$\begin{array}{c}\text { Total } \\
\left(\mathrm{MW}_{\text {th }}\right)\end{array}$} \\
\hline & $\begin{array}{c}\text { Beneficial } \\
\text { Geothermal } \\
\text { Heat }\left(\mathrm{MW}_{\mathrm{th}}\right) \\
\end{array}$ & $\begin{array}{c}\text { Mean } \\
\text { Resource } \\
\text { Energy } \\
\left(10^{18} \mathrm{~J}\right) \\
\end{array}$ & $\begin{array}{c}\text { Mean } \\
\text { Resource } \\
\text { Energy } \\
\left(10^{12} \text { Btu }\right)\end{array}$ & $\begin{array}{c}\text { Beneficial } \\
\text { Geothermal } \\
\text { Heat }\left(\mathrm{MW}_{\text {th }}\right)\end{array}$ & $\begin{array}{c}\text { Mean } \\
\text { Resource } \\
\text { Energy } \\
\left(10^{18} \mathrm{~J}\right)\end{array}$ & $\begin{array}{c}\text { Mean } \\
\text { Resource } \\
\text { Energy } \\
\left(10^{12} \text { Btu }\right)\end{array}$ & \\
\hline Washington & 75 & 0.158 & 150 & 0 & 0.000 & 0 & 75 \\
\hline Texas & 115 & 0.235 & 223 & 0 & 0.000 & 0 & 115 \\
\hline Wyoming & 129 & 0.475 & 450 & 0 & 0.000 & 0 & 129 \\
\hline New Mexico & 288 & 0.570 & 540 & 29 & 0.055 & 52 & 317 \\
\hline Colorado & 308 & 0.975 & 924 & 67 & 0.080 & 76 & 375 \\
\hline Alaska & 399 & 0.784 & 743 & 0 & 0.000 & 0 & 399 \\
\hline Montana & 428 & 0.838 & 794 & 0 & 0.000 & 0 & 428 \\
\hline Utah & 214 & 0.435 & 412 & 263 & 0.860 & 815 & 477 \\
\hline Oregon & 602 & 1.191 & 1,129 & 487 & 1.130 & 1,071 & 1,089 \\
\hline California & 937 & 1.847 & 1,751 & 271 & 1.547 & 1,466 & 1,208 \\
\hline Arizona & 426 & 0.846 & 802 & 829 & 1.767 & 1,675 & 1,255 \\
\hline Nevada & 863 & 1.683 & 1,595 & 1,055 & 2.231 & 2,115 & 1,918 \\
\hline Idaho & 1,361 & 2.676 & 2,536 & 728 & 1.425 & 1,351 & 2,089 \\
\hline TOTAL & 6,145 & 12.713 & 12,050 & 3,729 & 9.095 & 8,620 & 9,874 \\
\hline
\end{tabular}

Figure 14 illustrates the low-temperature geothermal beneficial potential overlaid with the corresponding potential desalination potential, assuming GOR $=4$. Idaho, Nevada, Arizona, California and Utah are the top five states. The predicted desalination potential in California is approximately $184,000 \mathrm{~m}^{3} /$ day (50 MGD), which is approximately equal to the capacity of the new Carlsbad Desalination Plant near San Diego [19]. 


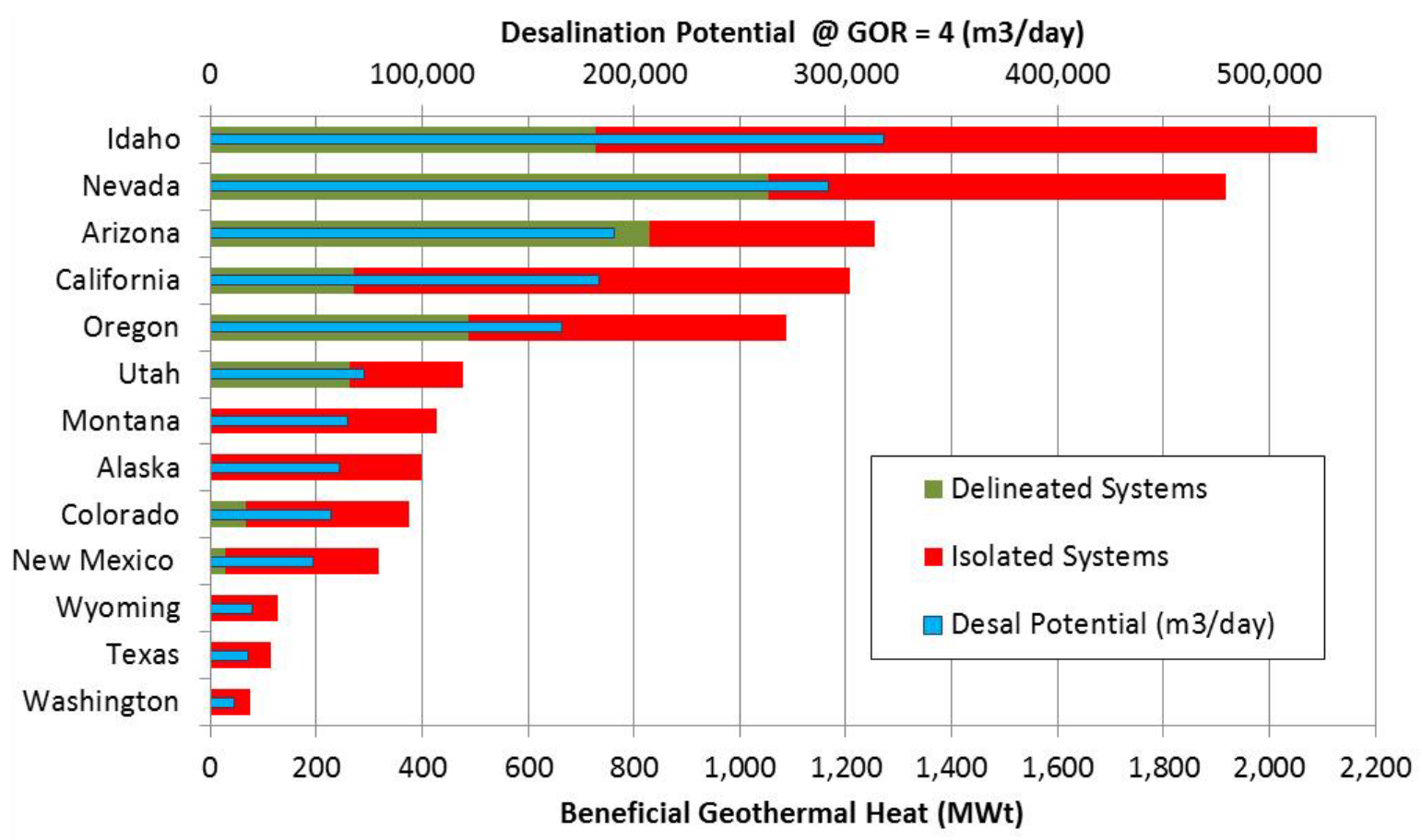

Figure 14. Estimated beneficial geothermal heat and desalination potential by states originating from hydrothermal convectional systems [17]. Desalination estimates assume GOR $=4$.

Based on the Oregon Institute of Technology Geo-Heat Center and other geothermal databases, there are more than 900 geothermal wells having temperatures between $50^{\circ} \mathrm{C}$ and $90^{\circ} \mathrm{C}$ in the United States (Figure 15). Most of these wells are already used for direct-heat applications. In addition to these wells, many more inactive and unproductive oil and gas wells can be used for thermal-energy production. An example of these wells is the Gulf No.1 well in Presidio, TX, which is $2073 \mathrm{~m}$ deep and has a temperature of $82^{\circ} \mathrm{C}$ and a flow rate of $138 \mathrm{~L} / \mathrm{s}$ [20]. 


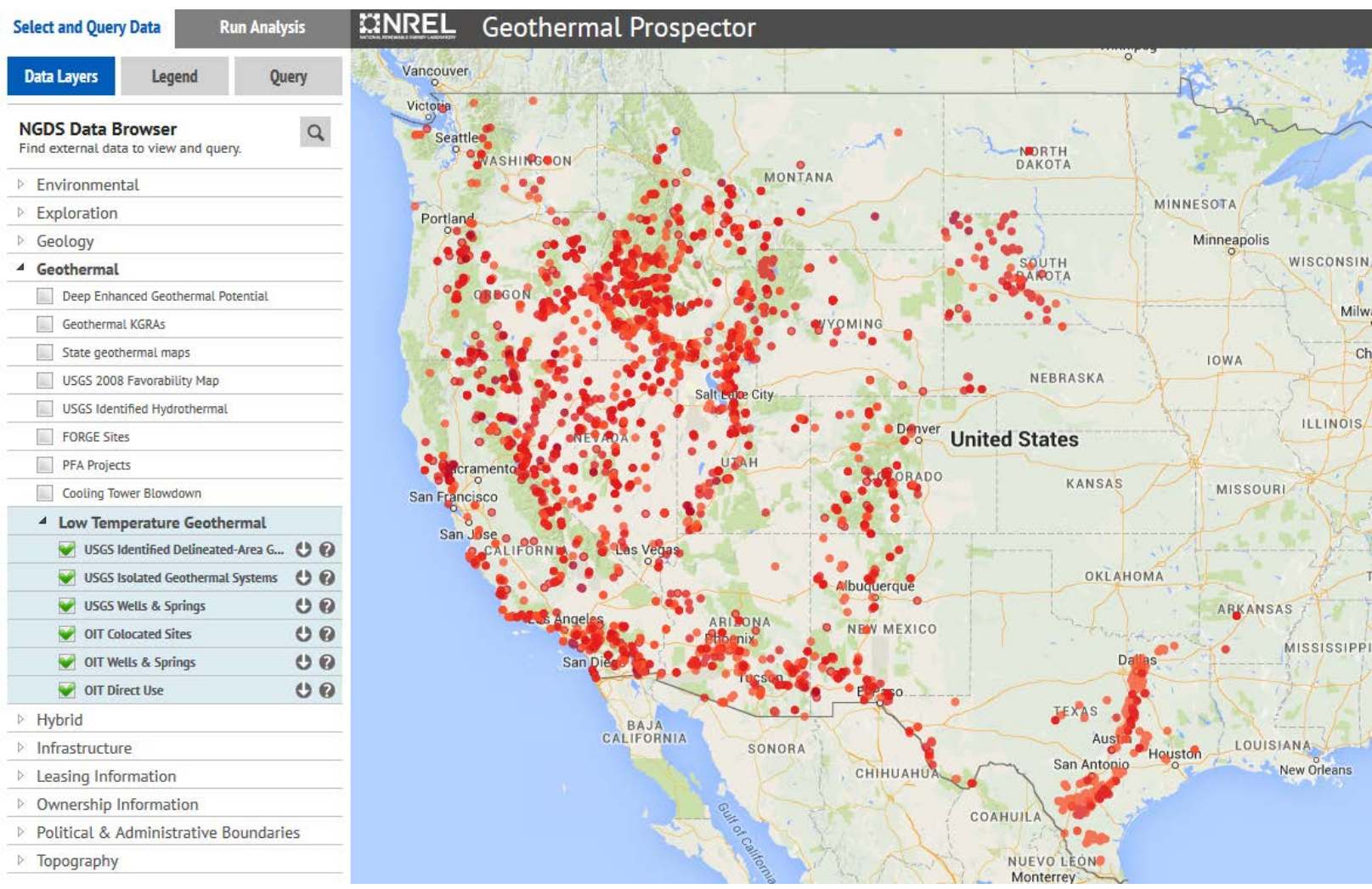

Figure 15. Distribution of low-temperature (between $50^{\circ} \mathrm{C}$ and $90^{\circ} \mathrm{C}$ ) geothermal wells suitable for MD technology.

\subsection{Thermal-Energy Cost}

The successful integration of MD with geothermal heat depends on that heat being available at very low cost. In this section, we estimate the cost of geothermal heat and compare it to other energy sources. Table 6 and Table 7 outline the estimated levelized cost of heat (LCOH) for different geothermal source cases. The $\mathrm{LCOH}$ is defined as a convenient metric for estimating lifetime cost for geothermal direct-use applications. $\mathrm{LCOH}$ is defined analogously to LCOE, which conventionally refers to electric energy. In its simplest form, $\mathrm{LCOH}$ is defined as:

$$
L C O H=\frac{(\text { Total installed project cost }) *(F C R)+(\text { Annual } O \& M)}{\text { Annual thermal generation }}
$$

where FCR is the fixed charge rate and depends on a range of financial parameters that can have a significant influence on LCOH. The latest release of NREL's System Advisor Model (SAM, version 2015-06-30) includes a procedure for estimating and using the FCR method, which is used in this study. More information on the approach is summarized in Appendix E. 
Table 6. Summary of LCOH estimates for different production scenarios from new geothermal wells*

\begin{tabular}{|c|c|c|c|c|c|}
\hline & Units & \multicolumn{4}{|c|}{ Case-1: New Geothermal Well } \\
\hline \multicolumn{2}{|l|}{ Geothermal Field Characteristics } & Scenario 1.1 & Scenario 1.2 & Scenario 1.3 & Scenario 1.4 \\
\hline Production Temperature & ${ }^{\circ} \mathrm{C}$ & 100 & 100 & 100 & 90 \\
\hline Re-Injection Temperature & ${ }^{\circ} \mathrm{C}$ & 70 & 70 & 70 & 60 \\
\hline Temperature Gradient & ${ }^{\circ} \mathrm{C} / 100 \mathrm{~m}$ & 5 & 6 & 7 & 5 \\
\hline Drilling Depth & $\mathrm{m}$ & 1500 & 1250 & 1071 & 1300 \\
\hline Flow Rate/well & $\mathrm{L} / \mathrm{s}$ & 89 & 89 & 89 & 87 \\
\hline Total Flow Rate & $\mathrm{L} / \mathrm{s}$ & 89 & 89 & 89 & 174 \\
\hline Thermal Energy Capacity & MWt & 11.15 & 11.15 & 11.15 & 21.80 \\
\hline Capacity Factor & $\%$ & $90 \%$ & $90 \%$ & $90 \%$ & $90 \%$ \\
\hline Annual Operational Hours & h & 7884 & 7884 & 7884 & 7884 \\
\hline Annual Production & kWht/yr & $87,906,600$ & $87,906,600$ & $87,906,600$ & $171,871,200$ \\
\hline \# Production Wells & & 1 & 1 & 1 & 2 \\
\hline \# Re-Injection Wells & & 1 & 1 & 1 & 1 \\
\hline \multicolumn{6}{|l|}{ CAPEX } \\
\hline Development Cost & $\$$ & $1,000,000$ & $1,000,000$ & $1,000,000$ & $1,000,000$ \\
\hline Drilling Cost (production or Re-injection) & $\$ /$ well & $2,250,003$ & $1,562,502$ & $1,147,961$ & $1,690,002$ \\
\hline Total Drilling Cost (1 prod. \& 1 Re-inj.) & $\$$ & $4,500,006$ & $3,125,005$ & $2,295,922$ & $5,070,007$ \\
\hline Well Head equipment Cost (total) & $\$$ & 300,000 & 300,000 & 300,000 & 500,000 \\
\hline Pump Cost (ESP) & $\$$ & 500,000 & 500,000 & 500,000 & $1,000,000$ \\
\hline Piping Cost* & $\$$ & 300,000 & 300,000 & 300,000 & 600,000 \\
\hline Total & $\$$ & $6,900,006$ & $5,525,005$ & $4,695,922$ & $8,670,007$ \\
\hline \multicolumn{6}{|l|}{ OPEX } \\
\hline Production Well Pumping (Electricity)* & $\$ / y r$ & 211,883 & 211,883 & 211,883 & 423,765 \\
\hline Inhibitor Cost & $\$ / y r$ & 50,000 & 50,000 & 50,000 & 100,000 \\
\hline Labor Cost & $\$ / y r$ & 150,000 & 150,000 & 150,000 & 150,000 \\
\hline Re-Injection Cost & $\$ / y r$ & 150,000 & 150,000 & 150,000 & 250,000 \\
\hline Total & $\$ / y r$ & 561,883 & 561,883 & 561,883 & 878,495 \\
\hline \multicolumn{6}{|l|}{ Financial Assumptions } \\
\hline Weighted average cost of capital & $\%$ & $6.2 \%$ & $6.2 \%$ & $6.2 \%$ & $6.2 \%$ \\
\hline Project life & years & 20 & 20 & 20 & 20 \\
\hline Calculated fixed charge rate & - & 0.101 & 0.101 & 0.101 & 0.101 \\
\hline Levelized Cost of Heat (LCOH) & $\$ /$ kWht & 0.0143 & 0.0127 & 0.0118 & 0.0102 \\
\hline Levelized Cost of Heat (LCOH) & $\$ / M M B t u$ & 4.2 & 3.7 & 3.5 & 3.0 \\
\hline
\end{tabular}

* Major assumptions: (i) 1000-m spacing between production and re-injection well, (ii) unit cost of insulated pipe $\$ 300 / \mathrm{m}$, (iii) $250-\mathrm{kW}$ average electricity consumption for a submersible pump to produce flow rate of $88 \mathrm{~L} / \mathrm{s}$, and (iv) 2014 commercial U.S. average electricity price of $10.7 \notin / \mathrm{kWh}$. 
Table 7. Summary of LCOH estimates for different production scenarios from existing geothermal wells and existing power plant cases*

\begin{tabular}{|c|c|c|c|c|c|}
\hline & Units & \multicolumn{2}{|c|}{ Case-2: Existing Geothermal Well } & \multicolumn{2}{|c|}{ Case-3: Existing Geothermal Power Plant } \\
\hline \multicolumn{2}{|l|}{ Geothermal Field Characteristics } & Scenario 2.1 & Scenario 2.2 & Scenario 3.1 & Scenario 3.2 \\
\hline Production Temperature & ${ }^{\circ} \mathrm{C}$ & 100 & 100 & 70 & 80 \\
\hline Re-Injection Temperature & ${ }^{\circ} \mathrm{C}$ & 70 & 60 & 50 & 50 \\
\hline Temperature Gradient & ${ }^{\circ} \mathrm{C} / 100 \mathrm{~m}$ & NA & NA & NA & $\mathrm{NA}$ \\
\hline Drilling Depth & $\mathrm{m}$ & NA & NA & NA & $\mathrm{NA}$ \\
\hline Flow Rate/well & L/s & 89 & 80 & NA & $\mathrm{NA}$ \\
\hline Total Flow Rate & L/s & 89 & 160 & 80 & 160 \\
\hline Thermal Energy Capacity & $\mathrm{MWt}$ & 11.15 & 26.70 & 7.4 & 13.4 \\
\hline Capacity Factor & $\%$ & $90 \%$ & $90 \%$ & $90 \%$ & $90 \%$ \\
\hline Annual Operational Hours & $\mathrm{h}$ & 7884 & 7884 & 7884 & 7884 \\
\hline Annual Production & kWht/yr & $87,906,600$ & $210,502,800$ & $58,341,600$ & $105,645,600$ \\
\hline \# Production Wells & & 1 & 2 & NA & $\mathrm{NA}$ \\
\hline \# Re-Injection Wells & & 1 & 1 & NA & $\mathrm{NA}$ \\
\hline \multicolumn{6}{|l|}{ CAPEX } \\
\hline Development Cost & $\$$ & 0 & 0 & 0 & 0 \\
\hline Drilling Cost (production or Re-injection) & $\$ /$ well & 0 & 0 & 0 & 0 \\
\hline Total Drilling Cost (1 prod. \& 1 Re-inj.) & $\$$ & 0 & 0 & 0 & 0 \\
\hline Well Head equipment Cost (total) & $\$$ & 300,000 & 500,000 & 0 & 0 \\
\hline Pump Cost (ESP) & $\$$ & 500,000 & $1,000,000$ & 100,000 & 100,000 \\
\hline Piping Cost* & $\$$ & 300,000 & 600,000 & 60,000 & 60,000 \\
\hline Total & $\$$ & $1,400,000$ & $2,600,000$ & 160,000 & 160,000 \\
\hline \multicolumn{6}{|l|}{ OPEX } \\
\hline Production Well Pumping (Electricity)* & $\$ / y r$ & 211,883 & 423,765 & 0 & 0 \\
\hline Inhibitor Cost & $\$ / y r$ & 50,000 & 100,000 & 100,000 & 150,000 \\
\hline Labor Cost & $\$ / y r$ & 150,000 & 150,000 & 30,000 & 30,000 \\
\hline Re-Injection Cost & $\$ / y r$ & 150,000 & 250,000 & 75,000 & 125,000 \\
\hline Total & $\$ / y r$ & 561,883 & 878,495 & 205,000 & 305,000 \\
\hline \multicolumn{6}{|l|}{ Financial Assumptions } \\
\hline Weighted average cost of capital & $\%$ & $6.2 \%$ & $6.2 \%$ & $6.2 \%$ & $6.2 \%$ \\
\hline Project life & years & 20 & 20 & 20 & 20 \\
\hline Calculated fixed charge rate & - & 0.101 & 0.101 & 0.101 & 0.101 \\
\hline Levelized Cost of Heat (LCOH) & $\$ /$ kWht & 0.0080 & 0.0054 & 0.0038 & 0.0030 \\
\hline Levelized Cost of Heat (LCOH) & \$/MMBtu & 2.3 & 1.6 & 1.1 & 0.9 \\
\hline
\end{tabular}

* Major assumptions: (i) 1000-m spacing between production and re-injection well, (ii) unit cost of insulated pipe $\$ 300 / \mathrm{m}$, (iii) $250-\mathrm{kW}$ average electricity consumption for a submersible pump to produce flow rate of $88 \mathrm{~L} / \mathrm{s}$, and (iv) 2014 commercial U.S. average electricity price of $10.7 \notin / \mathrm{kWh}$.

The cases in Table 6 and Table 7 cover three primary scenarios: (Case 1) new production and injection wells must be drilled for the geothermal resource, (Case 2) existing, but used, production and injection wells are used that must be completed and maintained, and (Case 3) geothermal heat is siphoned off an existing geothermal power plant prior to reinjection. Case 1 is further divided into different resource qualities similar to other work [21]. LCOH is estimated for the different cases using a set of financial assumptions taken from SAM's default values. The resulting $\mathrm{LCOH}$ ranges from $\$ 0.003 / \mathrm{kWh}_{\text {th }}$ to $\$ 0.014 / \mathrm{kWh}_{\text {th }}(\$ 0.9$ to $\$ 4.2 / \mathrm{MMBtu})$.

A convenient comparison for thermal-energy cost in the United States is a natural gas boiler. The estimated cost of thermal energy from a natural gas boiler compared to geothermal heat is shown in Figure 16. For the assumptions here, about $80 \%$ to $90 \%$ of the total levelized cost for the gas 
heat is due to fuel. In 2014, the average price for industrial natural gas in the United States was about \$5.5/MMBtu [22]. Figure 16 indicates that geothermal heat is clearly less expensive than heat from a gas boiler at those 2014 average gas prices. Furthermore, if existing, underutilized wells can be purposed for desalination, the cost of geothermal energy is about one-third that of heat from a gas boiler at current gas prices. The advantage is even greater if one considers the California market, where the average industrial gas price in 2014 was $\$ 7.7 / \mathrm{MMBtu}$ [22].

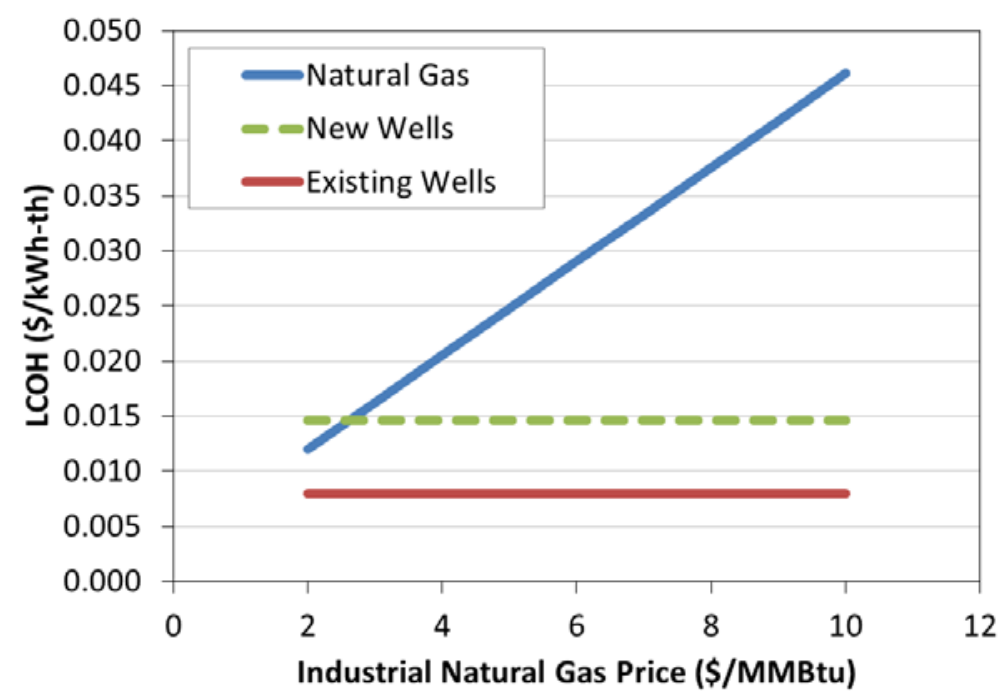

Figure 16. LCOH for natural gas boiler and geothermal sources as a function of industrial gas price. The calculation assumes an $80 \%$ boiler efficiency, $90 \%$ availability, and $\$ 270 / \mathbf{k W}_{\text {th }}$ installed capital cost. Geothermal assumptions are listed in Table 6 and Table 7.

The cost of thermal energy assumed in prior desalination cost studies is an important consideration. The work by Kesieme and co-workers [8], discussed previously, assumed a steam cost of $\$ 0.0124 / \mathrm{kWh}_{\mathrm{th}}$. This is a relatively low value compared to the estimated cost of heat from natural gas in Figure 16 and corresponds to a gas price of about \$2/MMBtu. Based on Kesieme's work, at the scale of $5,000 \mathrm{~m}^{3} /$ day, a thermal-energy cost of about $\$ 0.004 / \mathrm{kWh}_{\text {th }}$ is necessary for the MD technology to hit a product-water cost target of $\$ 1 / \mathrm{m}^{3}$. The thermal-energy cost to achieve $\$ 1.5 / \mathrm{m}^{3}$ is about $\$ 0.009 / \mathrm{kWh}$ th. Product-water costs are about $\$ 0.4 / \mathrm{m}^{3}$ higher at the smaller scale of $100 \mathrm{~m}^{3} /$ day.

Basically, thermal energy can be obtained from geothermal resource in three different cases: 1) drilling new wells in a proven resource area, 2) using existing geothermal wells that are actively used by the operators and not suitable for electricity generation, and 3) using outlet brine from existing geothermal power plants. Cost of thermal energy from geothermal resources is highly dependent on cost of drilling, resource potential, and fluid enthalpy from production wells. $\mathrm{LCOH}$ from new wells is estimated to range from $\$ 0.010$ to $\$ 0.014 / \mathrm{kWh}$ th (Table 6). The relatively high $\mathrm{LCOH}$ is related to the drilling cost. When an existing geothermal well is used, the $\mathrm{LCOH}$ can be lowered down to about $\$ 0.005$ to $\$ 0.008 / \mathrm{kWh}$ th (Table 7). Accessing unused low-temperature heat from a geothermal power plant offers the potential to achieve costs in the range of $\$ 0.003$ to $\$ 0.004 / \mathrm{kWh}_{\text {th }}$, which reaches Kesieme's cost target for $\$ 1 / \mathrm{m}^{3}$ MD product water. 
The cheapest source of thermal energy is excess heat coming from the outlet brine of geothermal power plants. In this case, capital costs include only a booster pump and interconnection piping, while operational costs include labor, re-injection pumping and chemical control (inhibitors). In the case of thermal-energy extraction from power-plant outlet brine, one should carefully investigate inhibitor optimization to prevent scaling and re-injection strategy for long-term production. 


\section{Cooling-Tower Blowdown as Source Water for Desalination}

One potential source of water for desalination, especially in the West, is blowdown water from thermo-electric power plants with cooling towers. In these power plants, a heat source (e.g., fossil, nuclear, solar, or geothermal) vaporizes water to steam. The steam exiting the power turbine is condensed by cooling for reuse in the steam cycle. Recirculating cooling towers are often used in the arid West to minimize the required withdrawal rate of water for cooling. In wetter, more humid regions, once-through cooling is common.

At plants using cooling towers, the cooling loop circulates water between the condenser and cooling tower, as seen in Figure 17. As water evaporates, dissolved solids are left behind, increasing their concentration in the recirculating water. Some water has to be "blown down" or ejected to regulate the amount of dissolved solids and salts, which can accumulate in the pipes and tower packing and corrode the equipment. This blowdown water must be treated or disposed of in a safe manner. Alternatively, the water could be recaptured, desalinated, and recirculated to the plant. This would increase the water efficiency of these power plants and decrease the ecological effects of water withdrawal in these arid regions of the western U.S.

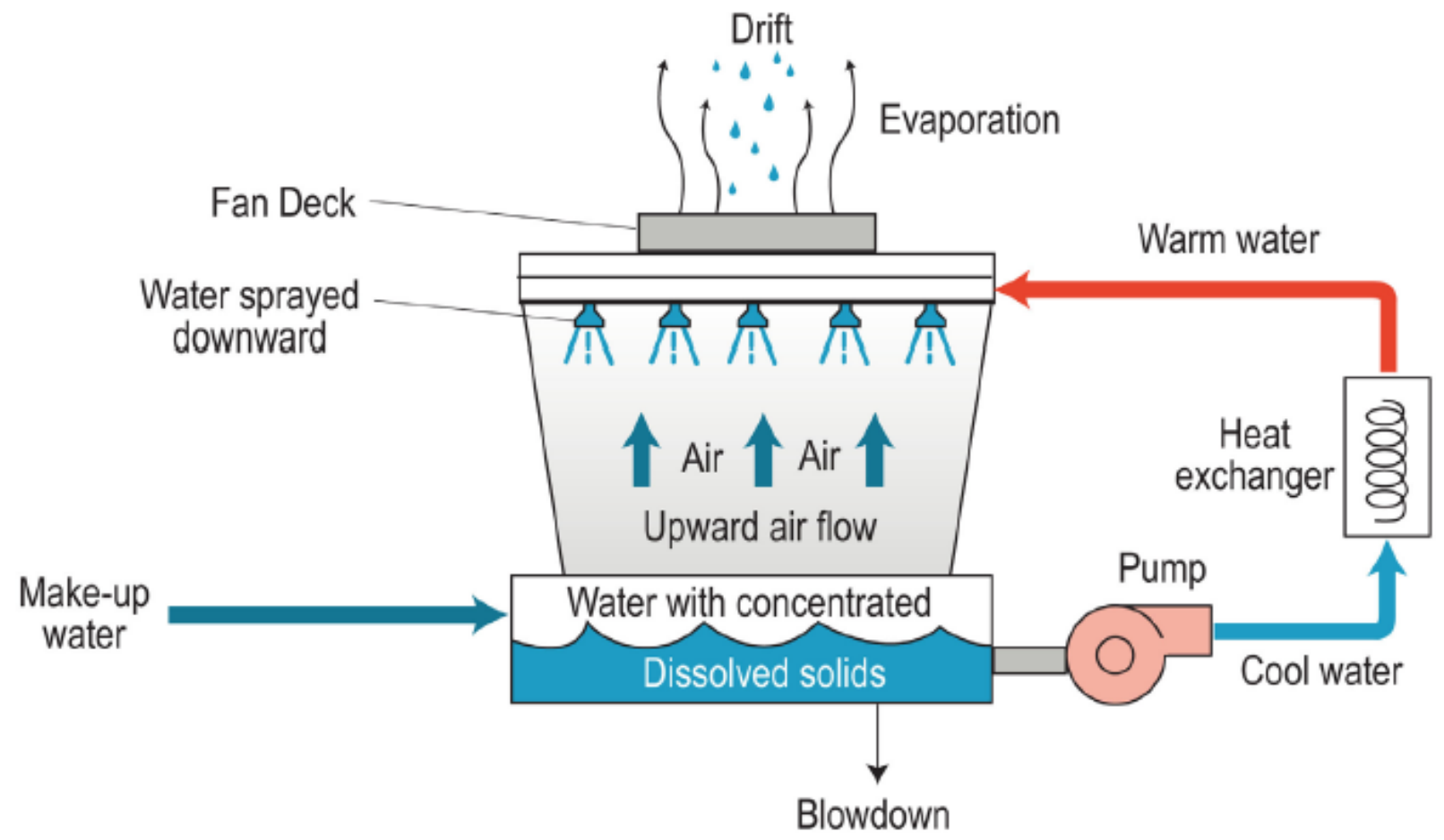

Figure 17. Typical configuration of a cooling tower at a thermo-electric power plant. The coolingtower loop interfaces with the turbine's water/steam loop via a heat exchanger. Water consumption comes from evaporation, blowdown, and to a lesser extent, loss of water droplets as drift [23].

To assess the potential of blowdown-water desalination, this study accessed a database from the Union of Concerned Scientists that covered thermo-electric power plants across the United States [24]. The data were narrowed by selecting for plants that used wet-cooling towers in eight western states: Washington, Oregon, California, Idaho, Nevada, Utah, Arizona, and New 
Mexico. The resulting 596 power plants were used to focus on the area of the western United States most impacted by long-standing droughts.

A preliminary estimate of blowdown flow volumes was made by calculating the difference between the "calculated withdrawal" and "calculated consumption," as reported within the database. This resulted in an estimated 60 billion gal $/ \mathrm{yr}\left(616,000 \mathrm{~m}^{3} /\right.$ day $)$, but yielded zero blowdown for many of these power plants, which is an unrealistic result. It was assumed that these sites were using blowdown evaporation ponds and not discharging any water from the site.

Consequently, the amount of annual blowdown was estimated from the cooling load for the different types of power plants. The efficiency of energy conversion from fuel source to electricity differs for each power-plant type, and knowing these efficiencies allows one to estimate the cooling loads. Once the cooling load is known, the level of water usage is dependent on the cycles of concentration within the cooling tower (see Figure 18). Cycles of concentration refers to how many times the cooling water passes through the tower before being evaporated or rejected in the blowdown flow. Higher cycles use less water, but the concentration of dissolved solids in the cooling water will increase, which could lead to scaling and fouling problems.

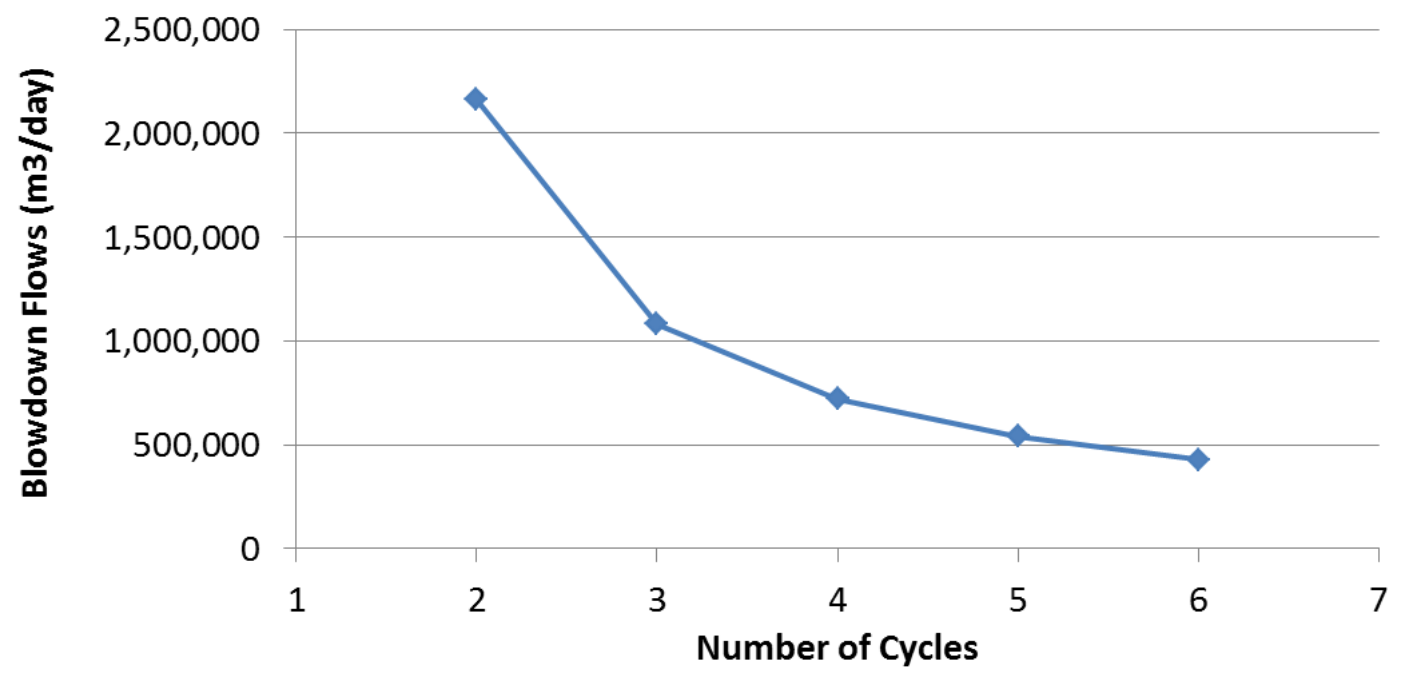

Figure 18. Total annual cooling tower blowdown volume for the eight western states in this study as a function of assumed cycles of concentration.

The power-plant database covered biomass, coal, geothermal, natural gas, nuclear, oil, and concentrating solar power (CSP) heat sources. The following assumptions were made as part of the calculation of blowdown water flows:

1. Power-plant thermo-electric efficiencies: biomass $=30 \%$, coal $=35 \%$, geothermal $=$ $15 \%$, natural gas combined-cycle $=55 \%$, nuclear $=30 \%$, oil $=35 \%$, CSP $=35 \%$ [25]

2. Blowdown $=$ Evaporation $\div($ Cycles of Concentration -1$)[26]$

3. Cooling systems operating between two and six cycles of concentration [27]. 
Not all power plants operate at the same number of cycles of concentration, so a range was used of two to six cycles of concentration. The resulting blowdown estimates for the eight states range from 42 to $208 \mathrm{Bgal} / \mathrm{yr}$ ( 0.43 to 2.16 million $\mathrm{m}^{3} /$ day), as depicted in Table 8 and Figure 19. For reference, the city of Golden, Colorado (population 20,000) uses about $1 \mathrm{Bgal} / \mathrm{yr}$, so the opportunity presented by treating blowdown water could represent the water supply of up to 69 small cities, assuming 4 cycles of concentration.

Table 8. Estimated annual blowdown volume by state in billion gallons per year for different assumed cycles of concentration

\begin{tabular}{|c|r|r|r|r|r|}
\hline Cycles of Concentration: & 2 cycles & 3 cycles & 4 cycles & 5 cycles & 6 cycles \\
\hline State & & & & & \\
WA & 14.8 & 7.4 & 4.9 & 3.7 & 3.0 \\
OR & 5.9 & 3.0 & 2.0 & 1.5 & 1.2 \\
CA & 59.0 & 29.5 & 19.7 & 14.8 & 11.8 \\
ID & 1.2 & 0.6 & 0.4 & 0.3 & 0.2 \\
NV & 9.6 & 4.8 & 3.2 & 2.4 & 1.9 \\
UT & 31.6 & 15.8 & 10.5 & 7.9 & 6.3 \\
AZ & 74.1 & 37.0 & 24.7 & 18.5 & 14.8 \\
NM & 11.7 & 5.8 & 3.9 & 2.9 & 2.3 \\
\hline Total (billion gal/yr): & 208 & 104 & 69 & 52 & 42 \\
\hline Total (m 3 /day): & $2,160,000$ & $1,080,000$ & 720,000 & 540,000 & 430,000 \\
\hline
\end{tabular}

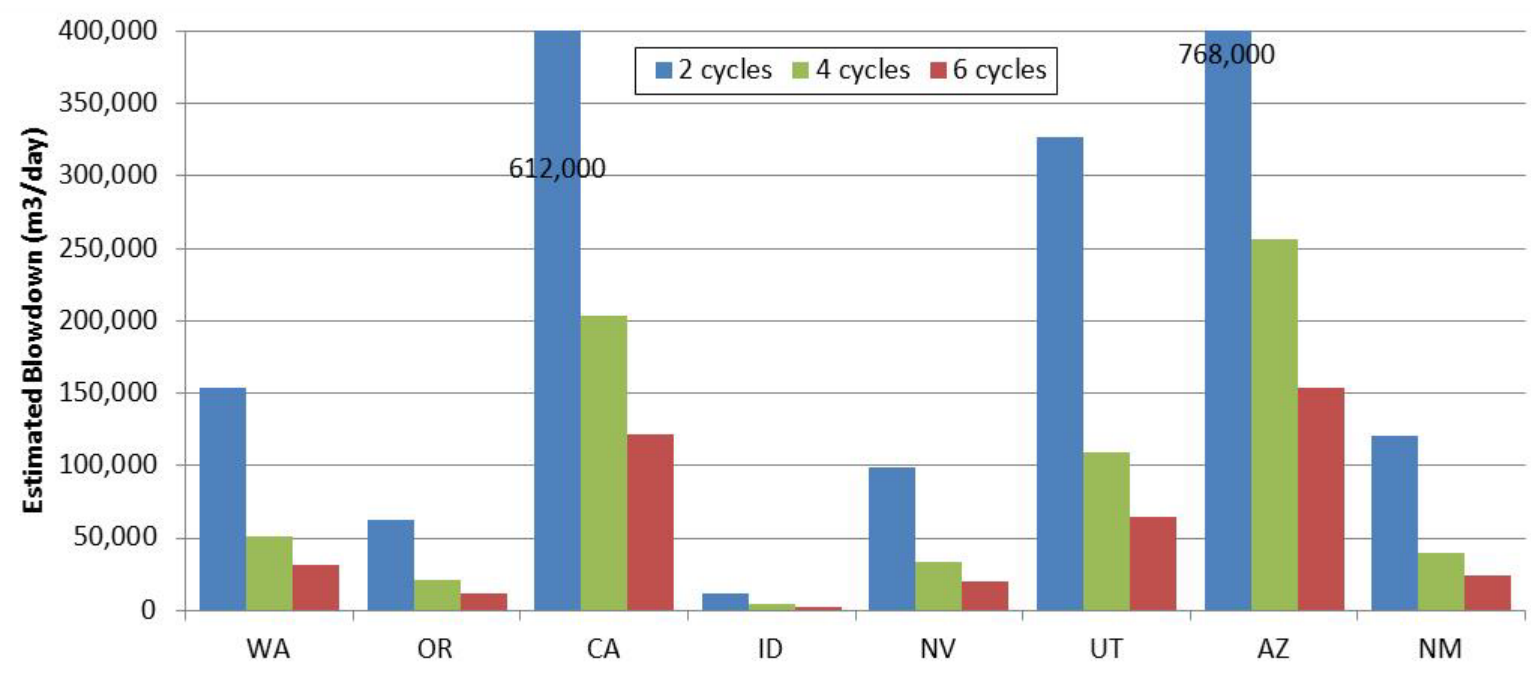

Figure 19. Estimated blowdown water volume as a function of assumed cycles of concentration for each western state.

Lastly, a map showing plant locations and estimated blowdown volumes assuming four cycles of concentration is shown in Figure 20. As a point of comparison, cooling-water requirements for geothermal power plants have been estimated at 2,000 gal/MWh $\left(7.57 \mathrm{~m}^{3} / \mathrm{MWh}\right)$, of which 1,400 gal $\left(5.30 \mathrm{~m}^{3}\right)$ of water is evaporated and consumed during the cooling process and $600 \mathrm{gal} / \mathrm{MWh}$ $\left(2.27 \mathrm{~m}^{3} / \mathrm{MWh}\right)$ is discharged as blowdown [28]. Based on these numbers, blowdown water for a 
$10 \mathrm{MW}_{\mathrm{e}}$ wet-cooled binary geothermal plant is estimated as $130,000 \mathrm{gal} /$ day. Treating and making a portion of this water available for plant operations would reduce the cost to reinject the wastewater as well as avoid the cost of fresh water purchase.

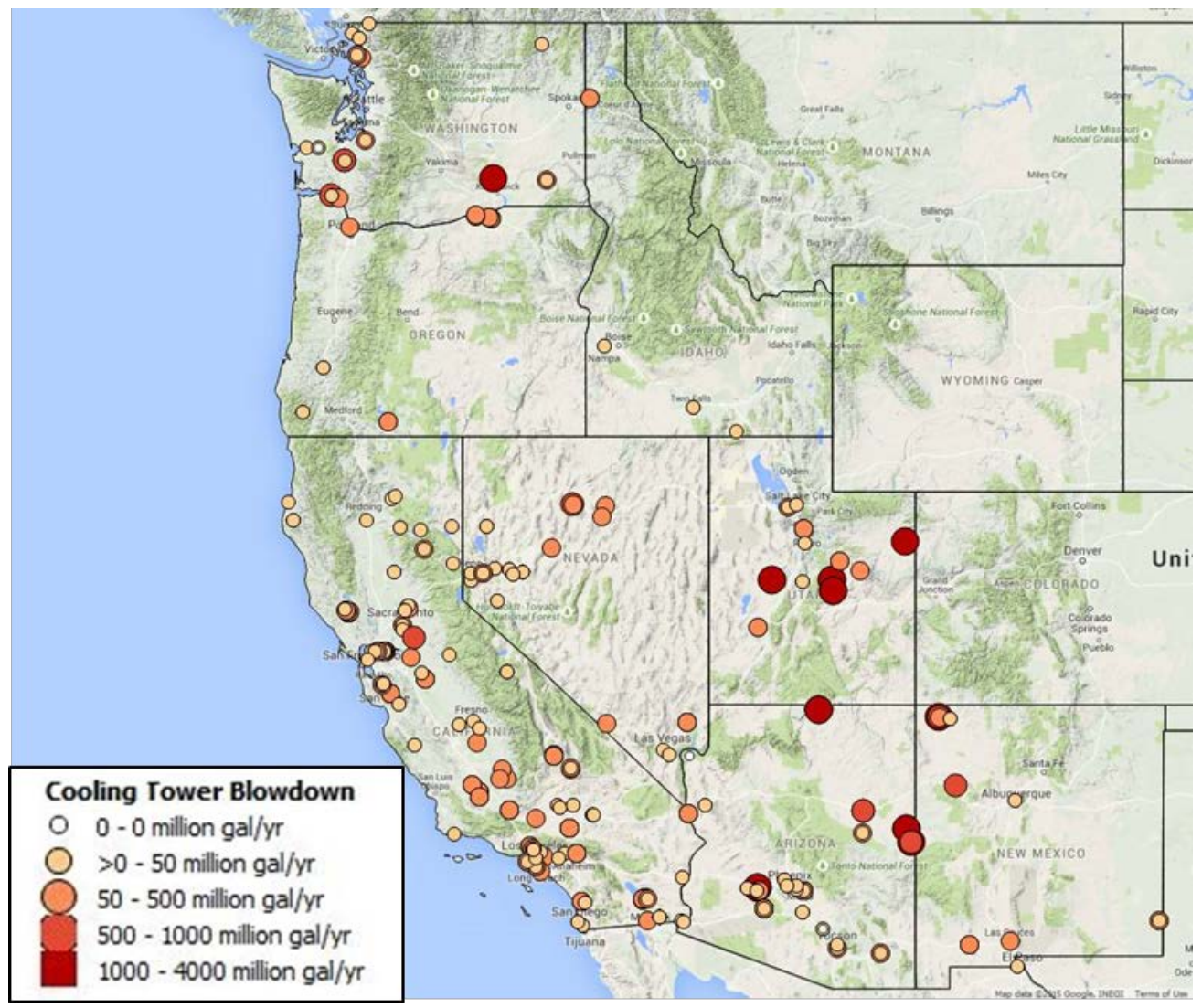

Figure 20. Google Maps overlay of thermo-electric power plants in the western United States that use cooling towers. The colors and sizes displayed represent estimated blowdown-water flow rates. () 2015 Google, Map Data

Discussion with geothermal developers identified cooling tower blowdown water as a source water of interest for desalination and reuse. The blowdown water is available onsite, must be disposed of, and could be processed with unused geothermal heat also available onsite.

Production of a fresh water stream would offset water cost for staff operations at the site and could extend the cycles of concentration within the cooling tower loop. 


\section{Future Work}

NREL, in collaboration with CSM and other partners, has proposed to pilot-test MD using geothermal energy. The overall goal of the project is to demonstrate the efficacy and to quantify the cost of using low-temperature geothermal resources to directly heat an MD system to produce high-quality water. The technology benefits will be quantified by the combination of avoided treatment/disposal cost of the source water and the value of the product water. A field test of geothermal-MD is expected to have the following outcomes:

- Demonstrate the integration of MD with geothermal energy,

- Develop a performance model and validate membrane flux estimates with commercialscale modules under field conditions at different operating conditions,

- Demonstrate durability and performance of the membranes and membrane modules,

- Test and evaluate antiscaling and/or antifouling coatings applied to commercial membranes,

- Estimate cost of product water based on membrane performance and a sensitivity analysis to the cost of geothermal heat. Define conditions that lead to costs of less than $\$ 1 / \mathrm{m}^{3}$ or otherwise provide economic viability. Describe and quantify applications beneficial to the geothermal industry.

The proposed demonstration project includes two national laboratories, two universities, and two industry partners. Participants and primary responsibilities are listed in Table 9.

Table 9. Partners in the proposed geothermal-MD demonstration project

\begin{tabular}{ll}
\hline NREL & $\begin{array}{l}\text { - Project management } \\
\text { - Techno-economic and opportunity-potential analysis } \\
\text { - Field-test support }\end{array}$ \\
\hline Colorado School of Mines (CSM) & • Laboratory and field testing \\
\hline Sandia National Laboratories & • Performance-model development \\
\hline $\begin{array}{l}\text { Univ. of California Riverside } \\
\text { (UCR) }\end{array}$ & - Membrane coating and optimization \\
\hline Ormat Technologies & - Potential site host and technology user \\
\hline GE Power \& Water & $\bullet$ MD technology developer/supplier \\
\hline
\end{tabular}




\section{Conclusions}

This joint project between NREL and the Colorado School of Mines has examined the potential of using low-temperature geothermal resources for desalination. The temperature range in question, less than about $100^{\circ} \mathrm{C}$, is not well suited for electricity generation, but can be used for direct heating. Accordingly, the best integration approaches use thermal desalination technologies such as multi-effect distillation or membrane distillation, rather than electric-driven technologies such as reverse osmosis.

The examination of different desalination technologies led to the selection of MD for pairing with geothermal energy. MD operates at near-ambient pressure and temperatures less than $100^{\circ} \mathrm{C}$ with hydrophobic membranes. The technology is modular like RO, but the equipment costs are lower. The thermal-energy demands of MD are higher than MED, but this is offset by an ability to run at lower temperatures and a low capital cost. Consequently, a geothermal MD system could offer a low capital cost and, if paired with low-cost geothermal energy, a low operating cost. Literature reviews suggest product-water cost could be less than $\$ 1 / \mathrm{m}^{3}$ if thermal energy is inexpensive. Such a cost is competitive with the best desalination applications in the world. Furthermore, the MD technology is suited for small-scale installations, and although small plant capacity increases water cost per $\mathrm{m}^{3}$, the scale is ideally suited for application in rural areas with modest-size geothermal resources.

The economics of desalination remain challenging regardless of technology. For example, the current wholesale cost for small-scale thermal desalination is on the order of $\$ 2-\$ 3 / \mathrm{m}^{3}$, which is at the high end of retail water rates in major U.S. cities. Product water from the new Carlsbad Desalination Project, a large RO plant in southern California, is expected to cost about $\$ 1.7 / \mathrm{m}^{3}$, which is stated to be about twice the cost of alternative water sources [19], [29]. Consequently, desalination is best applied where high-quality product water is valued and the impaired source water requires treatment for disposal. Such a situation provides two sources of "revenue" for the process - valuable product water and avoided treatment costs. The deployment of desalination as a hedge against future water scarcity, despite its relative cost, is sometimes listed as an additional supporting factor.

These "dual-revenue" conditions may exist for produced and flowback water from oil and gas operations, industrial wastewater, and locations where zero-water discharge is required or preferred. Thermal desalination processes can tolerate water of much higher TDS than RO systems, so locations striving for zero-discharge of wastewater or wishing to extract additional water from RO reject brine also would be amenable to geothermal desalination.

Based on these considerations, the treatment of cooling-tower blowdown water has been selected as an appealing application for demonstration of geothermal MD, and a potential site has been identified and proposed to the DOE GTO. The proposed project will access cooling-tower blowdown water at a geothermal power plant and use geothermal heat in a small-scale MD process. While this is a relatively small market opportunity, it is one of particular interest to the geothermal industry and provides a useful proving ground for the MD technology. Objectives include the following:

- Demonstrate the integration of MD with geothermal energy, 
- Develop a performance model and validate membrane flux estimates with commercialscale modules under field conditions at different operating conditions,

- Demonstrate long-term life and performance of the membranes and membrane modules,

- Test and evaluate antiscaling and/or antifouling coatings applied to commercial membranes, and

- Estimate cost of product water based on membrane performance and a sensitivity analysis to the cost of geothermal heat. Define conditions that lead to costs of less than $\$ 1 / \mathrm{m}^{3}$ or otherwise provide economic viability. Describe and quantify applications beneficial to the geothermal industry.

Based on low-temperature geothermal resource assessment estimates by the USGS [17], total resource capacity for identified hydrothermal systems having a mean reservoir temperature between $50^{\circ} \mathrm{C}$ and $90^{\circ} \mathrm{C}$ is more than $9,800 \mathrm{MW}$ th. USGS is revisiting this assessment, and an updated version will be released in late 2015 or 2016. In total, 13 states have potential for lowtemperature hydrothermal resources (excluding sedimentary basins and enhanced geothermal systems), with Idaho, Nevada, Arizona, California, and Utah ranking as the highest potential. Other states with low-temperature geothermal potential are Montana, Alaska, Colorado, New Mexico, Wyoming, Texas, and Washington. At present, only a small portion of these resources are in use for direct-heat applications. 


\section{References}

[1] J. S. Famiglietti and M. Rodell, "Water in Balance," Science, vol. 340, no. 6138, pp. 1300-1301, 2013.

[2] U.S. Bureau of Reclamation, "Desalination and Water Purification Technology Roadmap - A Report of the Executive Committee," Washington, DC, 2003.

[3] Colorado School of Mines, "An Integrated Framework for Treatment and Management of Produced Water: Technical Assessment of Produced Water Treatment Technologies.," 2009. [Online]. Available: http://aqwatec.mines.edu/produced_water/treat/docs/Tech_Assessment_PW_Treatment_Tech.pdf.

[4] U.S. Environmental Protection Agency, "Guidelines for water reuse," U.S. EPA, Report:625 R04, 2004.

[5] R. S. Ayers and D. W. Westcot, "Water Quality for Agriculture," Food and Agriculture Organization of the United Nations: Irrigation and Drainage Paper, 29 Rev. 1, 1994.

[6] T. D. Wolfe, "Total Flux and Scaling Program: A Membrane System Design Assistant," U.S. Environmental Protection Agency, Water Supply and Water Resources Division Agency, Project 9C-R193-NTSX, Cincinnati, OH, 2000.

[7] J. Ziolkowska, "Is Desalination Affordable?—Regional Cost," Water Resource Management, vol. 29, pp. 1385-1397, 2015.

[8] U. K. Kesieme, N. Milne, H. Aral, C. Y. Cheng and M. Duke, "Economic analysis of desalination technologies in the context of carbon pricing, and opportunities for membrane distillation," Desalination, vol. 323, pp. 66-74, 2013.

[9] "Energy Requirements of Desalination Processes," DESWARE, Encyclopedia of Desalination and Water Resources, [Online]. Available: http://www.desware.net. [Accessed 5 March 2015].

[10] J. Walton, H. Lu, C. Turner, S. Solis and H. Hein, "Solar and Waste Heat Desalination by Membrane Distillation; Desalination and Water Purification," Bureau of Reclamation, Denver, Colorado, 2004.

[11] L. Camacho, L. Dumee, J. Zhang, J. Li and M. Duke, "Advances in Membrane Distillation for Water Desalination and Purification Applications," Water, pp. 94-196, 2013.

[12] Memsys, "FAQ - frequently asked questions," [Online]. Available: http://www.memsys.eu/faq.html. [Accessed 5 May 2015].

[13] S. Al-Obaidani, E. Curcio, F. Macedonio, G. DiProfio, H. Al-Hinai and E. Drioli, "Potential of membrane distillation in seawater desalination: Thermal efficiency, sensitivity study and cost estimation," Journal of Membrane Science, vol. 323, no. 1, pp. 85-98, 2008.

[14] A. Ai-Karaghouli and L. Kazmerski, "Energy consumption and water production cost of conventional and renewable-energy-powered desalination processes," Renewable and Sustainable Energy Reviews, vol. 24, pp. 343-356, 2013.

[15] A. Hausmann, P. Sanciolo, T. Vasiljevic, M. Weeks and M. Duke, "Integration of membrane distillation into heat paths of industrial processes," Chemical Engineering Journal, Vols. 211-212, pp. 378-387, 2012.

[16] N. Dow, J. Zhang, M. Duke, J. Li, S. R. Gray and E. Ostarcervic, "Membrane Distillation of Brine," CRC for Water Quality and Treatment, Adelaide, Asutralia, 2008. 
[17] United States Geological Survey, "Assessment of Low-Temperature Geothermal Resources of the United States," USGS Circular 892, Alexandria, VA, 1982.

[18] C. F. Williams, J. DeAngelo and M. J. Reed, "Revisiting the Assessment of Geothermal Resources <90C in the United States," in Geothermal Resources Council 39th Annual Meeting, Reno, NV, 2015.

[19] San Diego County Water Authority, "Seawater Desalination: Carlsbad Desalination Project," sdcwa.org, San Diego, California, Factsheet March 2015.

[20] Oregon Institute of Technology Geo-Heat Center, "Geothermal Database," 2004.

[21] K. F. Beckers, M. Z. Lukawski, B. J. Anderson, M. C. Moore and J. Tester, "Levelized costs of electricity and direct-use heat from Enhanced Geothermal Systems," Journal of Renewable and Sustainable Energy, vol. 6, 2014.

[22] U.S. Energy Information Agency, "Natural Gas Prices, Industrial Price," [Online]. Available: http://www.eia.gov/dnav/ng/ng_pri_sum_a_epg0_pin_dmcf_a.htm. [Accessed September 2015].

[23] U.S. Department of Energy, "Cooling Towers: Understanding Key Components of Cooling Towers and How to Improve Water Efficiency," U.S. Department of Energy, DOE/PNNL-SA$75820,2011$.

[24] Union of Concerned Scientists, "Freshwater Use by U.S. Power Plants: Electricity's Thirst for a Precious Resource," 2011. [Online]. Available: http://www.ucsusa.org/clean_energy/our-energychoices/energy-and-water-use/freshwater-use-by-us-power-plants.html\#.VfGyBkZa3K0. [Accessed August 2015].

[25] R. Bedilion, "Program on Technology Innovation: Integrated Generation Technology Options 2012," Electric Power Research Institute, Palo Alto, CA, 2013.

[26] San Jose/Santa Clara Water Pollution Control plant and the City of San Jose Environmental Service Department, "Guidelines for Managing Water in Cooling Systems," 2002.

[27] J. C. Hensley, "Cooling Tower Fundamentals, 2nd ed.," SPX Cooling Technologies, Inc., Overland Park, KS, 2009.

[28] C. Clark, C. B. Harto, J. L. Sullivan and M. Q. Wang, "Water Use in Development and Operation of Geothermal Power Plants," Argonne National Laboratory, 2010.

[29] W. Short, D. J. Packey and T. Holt, "A Manual for the Economic Evaluation of Energy Efficiency and Renewable Energy Technologies," National Renewable Energy Laboratory, NREL/TP-4625173, Golden, Colorado, 1995. 


\section{Appendix}

\section{Appendix A - Objectives Categories used in GDsalt}

Table A1. Monetary objectives cost categories and basis

\begin{tabular}{|c|c|}
\hline Items & Remark/basis for facility capital cost estimation \\
\hline \multicolumn{2}{|l|}{ Facility Capital Costs } \\
\hline Treatment technology & Plant capacity \\
\hline Pipelines & Pipe length and unit cost \\
\hline Pump Stations & Flow rate, TDH lift, efficiency \\
\hline Storage Facility & Storage type, volume, cost curves \\
\hline Buildings & Capacity/flow rate \\
\hline New Beneficial Use Infrastructure & Flow rate \\
\hline Site Development Costs & $\%$ of capital costs \\
\hline Yard Piping & $\%$ of capital costs \\
\hline Electrical & $\%$ of capital costs \\
\hline \multicolumn{2}{|l|}{ Annual Operations and Maintenance } \\
\hline Energy Costs, treatment & Capacity, period of operation \\
\hline Energy Costs, conveyance & Flow rate, TDH lift, efficiency, hours of operation/yr \\
\hline Labor Costs, treatment facility & Salaries, wages \\
\hline Chemicals; acid, base & Hours of operation/year, plant capacity, alkalinity(for acid) \\
\hline \multicolumn{2}{|l|}{ Treatment Supplies } \\
\hline Membrane costs & Annual replacement cost \\
\hline Materials and Supplies & $\%$ of capital costs \\
\hline Land lease & Typical BLM lease rate for one acre for one year \\
\hline Other O\&M costs & $\%$ of capital costs \\
\hline
\end{tabular}

Table A2. Non-monetary criteria

\begin{tabular}{|l|l|}
\hline Description & Explanation \\
\hline Operator oversight & Degree of operator oversight required \\
\hline Ease of operation & Hazardous chemicals and operator skill required to manage the system \\
\hline Flexibility & Ability of the technology to withstand highly variable water quality \\
\hline Footprint & Size, in land area, that the process takes up \\
\hline Industrial status & Market maturity, frequency of use, competitiveness of vendors \\
\hline Chemical demand & Volume of chemicals required at the site \\
\hline Energy demand & Specific energy required by the technology \\
\hline Mobility & Ease of moving a technology from one part of the site to another \\
\hline Modularity & Ability to implement a unit process and handle variable influent volume \\
\hline Robustness & Ability to withstand varying environmental conditions \\
\hline Waste management & Volume of waste and the technical skill required to handle it \\
\hline Energy recovery & Ability to recover energy \\
\hline Material recovery & The ability to recover materials \\
\hline
\end{tabular}




\section{Appendix B - Beneficial-Use Water-Quality Requirements}

Table B1. Beneficial-use water-quality requirements

\begin{tabular}{|c|c|c|c|c|c|}
\hline Constituent & Units & $\begin{array}{l}\text { Potable } \\
\text { Use }\end{array}$ & Livestock & $\begin{array}{c}\text { Crop } \\
\text { Irrigation }\end{array}$ & $\begin{array}{c}\text { Surface Water } \\
\text { Discharge }\end{array}$ \\
\hline Alkalinity (as $\mathrm{CaCO}_{3}$ ) & $\mathrm{mg} / \mathrm{L}$ & & & & \\
\hline Alkalinity-Bicarbonate & $\mathrm{mg} / \mathrm{L}$ & & & & \\
\hline Alkalinity-Carbonate & $\mathrm{mg} / \mathrm{L}$ & & & & \\
\hline Aluminum & $\mathrm{mg} / \mathrm{L}$ & & 5.00 & 5.00 & \\
\hline Arsenic & $\mathrm{mg} / \mathrm{L}$ & 0.01 & 0.20 & 0.10 & \\
\hline Barium & $\mathrm{mg} / \mathrm{L}$ & 2.00 & & & \\
\hline Benzene & $\mathrm{mg} / \mathrm{L}$ & 5.00 & & & \\
\hline Boron & $\mathrm{mg} / \mathrm{L}$ & & 5.00 & 1 & 2 \\
\hline Bromide & $\mathrm{mg} / \mathrm{L}$ & & & & \\
\hline Calcium & $\mathrm{mg} / \mathrm{L}$ & & & & \\
\hline Chloride & $\mathrm{mg} / \mathrm{L}$ & & & 70.00 & 1500 \\
\hline Chlorobenzene & $\mathrm{mg} / \mathrm{L}$ & & & & \\
\hline Chromium, total & $\mathrm{mg} / \mathrm{L}$ & 0.10 & 1.00 & 0.10 & \\
\hline Copper & $\mathrm{mg} / \mathrm{L}$ & 1.30 & 1 & 0 & 0 \\
\hline Cyanide & $\mathrm{mg} / \mathrm{L}$ & 0.15 & & & \\
\hline Ethylbenzene & $\mathrm{mg} / \mathrm{L}$ & 0.70 & & & \\
\hline Ethylene Dibromide & $\mathrm{mg} / \mathrm{L}$ & & & & \\
\hline Fluoride & $\mathrm{mg} / \mathrm{L}$ & 4.00 & 2.00 & 1.00 & \\
\hline Iron (II) & $\mathrm{mg} / \mathrm{L}$ & 0.30 & & 5.00 & 5.00 \\
\hline Iron (III) & $\mathrm{mg} / \mathrm{L}$ & 0.30 & & 5.00 & 5.00 \\
\hline Lead & $\mathrm{mg} / \mathrm{L}$ & 0.02 & 0.10 & 5.00 & \\
\hline Lithium & $\mathrm{mg} / \mathrm{L}$ & & & 15.00 & \\
\hline Magnesium & $\mathrm{mg} / \mathrm{L}$ & & 250 & & \\
\hline Manganese & $\mathrm{mg} / \mathrm{L}$ & 0.10 & 0.05 & 0.20 & 0.20 \\
\hline Mercury & $\mathrm{mg} / \mathrm{L}$ & & & & \\
\hline Molybdenum & $\mathrm{mg} / \mathrm{L}$ & & & & \\
\hline Nickel & $\mathrm{mg} / \mathrm{L}$ & & & 0.20 & \\
\hline Nitrate (as N) & $\mathrm{mg} / \mathrm{L}$ & & 10.00 & & \\
\hline Nitrite (as N) & $\mathrm{mg} / \mathrm{L}$ & & & & \\
\hline Oil and Grease & $\mathrm{mg} / \mathrm{L}$ & & & & \\
\hline o-Phosphate & $\mathrm{mg} / \mathrm{L}$ & & & & \\
\hline Potassium & $\mathrm{mg} / \mathrm{L}$ & & & & \\
\hline Radioactivity, Gross Alpha & $\mathrm{pCi} / \mathrm{L}$ & 15.00 & & & \\
\hline Radioactivity, Gross Beta & $\mathrm{pCi} / \mathrm{L}$ & 4.00 & & & \\
\hline Radium-226 + Radium-228 & $\mathrm{pCi} / \mathrm{L}$ & 5.00 & & & \\
\hline $\mathrm{Rd} 226+222+228$ & $\mathrm{pCi} / \mathrm{L}$ & & & & \\
\hline Selenium & $\mathrm{mg} / \mathrm{L}$ & 0.05 & 0.05 & 0.02 & 0.02 \\
\hline Silica $\left(\mathrm{SiO}_{2}\right)$ & $\mathrm{mg} / \mathrm{L}$ & & & & \\
\hline Silver & $\mathrm{mg} / \mathrm{L}$ & & & & \\
\hline Sodium & $\mathrm{mg} / \mathrm{L}$ & & & & \\
\hline Specific Conductance & $\mathrm{uS} / \mathrm{cm}$ & & & & \\
\hline Strontium & $\mathrm{mg} / \mathrm{L}$ & & & & \\
\hline Sulfate & $\mathrm{mg} / \mathrm{L}$ & & 1000 & & \\
\hline TDS (calc) & $\mathrm{mg} / \mathrm{L}$ & 500 & 5000 & 1500 & 3500 \\
\hline Toluene & $\mathrm{mg} / \mathrm{L}$ & & & & \\
\hline Total Nitrogen (as N) & $\mathrm{mg} / \mathrm{L}$ & & 10.00 & & \\
\hline Total Organic Carbon (TOC) & $\mathrm{mg} / \mathrm{L}$ & & & & \\
\hline Total Petroleum Hydrocarbons & $\mathrm{mg} / \mathrm{L}$ & & & & \\
\hline Total Suspended Solids (TSS) & $\mathrm{mg} / \mathrm{L}$ & & & & 30.00 \\
\hline Uranium & ug/L & 0.30 & & & \\
\hline Xylenes (total) & $\mathrm{mg} / \mathrm{L}$ & 10.00 & & & \\
\hline Zinc & $\mathrm{mg} / \mathrm{L}$ & & 24.00 & 2.00 & 2.00 \\
\hline
\end{tabular}




\section{Appendix C - Sensitivity Analysis of GDsalt}

Beyond the test cases described in the body text, additional test cases were analyzed using GDsalt to explore the sensitivity of the results to varying inputs. Two parameters were altered to demonstrate the functionality of GDsalt: percent water recovery and the criteria weighting for cost. GDsalt was tested at two water-recovery rates: 20\% and 85\%. Membrane processes are more sensitive to reject water TDS concentration than the thermal processes; thus, under higher water recovery, thermal processes should be preferentially selected depending on feed-water TDS concentration, everything else being equal. With lower water recovery, it is possible that membrane technologies are selected even for relatively high feed-water TDS values.

Additionally, user-assigned criteria weights for capital and O\&M cost were changed from the default value of 4 to a criteria weight of 1 , thereby increasing the importance of these criteria. All other criteria weights were kept constant. The results of the sensitivity analysis are presented below.

The results demonstrated that GDsalt is sensitive to changes in percent water recovery, with lower water recovery leading to selection of membrane processes instead of thermal processes when feed-water concentration is not very high. GDsalt tends to suggest a membrane process unless limited by water recovery or high temperature mainly because the membrane processes cost less and are preferred in terms of many other criteria listed in Table A2.

GDsalt was not very sensitive to changes in weights assigned to capital and O\&M costs; similar treatment trains were suggested regardless of the weights assigned to cost. (These scenarios are not presented in the Appendix). One reason for this result may be that the treatment selection was governed by performance constraints. Parametric and sensitivity analysis of GDsalt will continue to be explored in FY15.

The Imperial Valley groundwater test cases (Table C1) exhibited a wide range in TDS concentration. Consequently, this difference in TDS level dominated the selection, and the required water-recovery percentage did not affect technology selection. For the $25^{\text {th }}$-percentile case, GDsalt selected identical, non-thermal processes at both the $85 \%$ and $20 \%$ water recovery. The other two cases (mean and $75^{\text {th }}$-percentile source-water quality) had much higher TDS, which triggered selection of thermal processes irrespective of the recovery. Mechanical vapor compression remained an option for all cases.

Table C1. GDsalt results for Imperial Valley groundwater - effect of specified recovery

\begin{tabular}{|l|c|c|c|c|}
\hline \multirow{2}{*}{$\begin{array}{l}\text { Source Water } \\
\text { Imperial Valley } \\
\text { Groundwater }\end{array}$} & Pretreatment & Desalination & Pretreatment & Desalination \\
\cline { 2 - 5 } $\begin{array}{l}25^{\text {th }} \text { percentile } \\
\text { TDS }=1,500 \mathrm{mg} / \mathrm{L}\end{array}$ & Media Filter & BWRO, SWRO, or MVC & Media filter & BWRO, SWRO, or MVC \\
\hline $\begin{array}{l}\text { Mean } \\
\text { TDS }=195,000\end{array}$ & $\begin{array}{c}\text { Chemical } \\
\text { softening and } \\
\text { mg/L }\end{array}$ & MVC, MED, or TVC & $\begin{array}{c}\text { Chemical } \\
\text { softening and } \\
\text { media filter }\end{array}$ & MVC, MED, or TVC \\
\hline $\begin{array}{l}75^{\text {th }} \text { percentile } \\
\text { TDS }=390,000 \\
\mathrm{mg} / \mathrm{L}\end{array}$ & $\begin{array}{c}\text { Chemical } \\
\text { softening and } \\
\text { media filter }\end{array}$ & MVC, MED, or TVC & $\begin{array}{c}\text { Chemical } \\
\text { softening and } \\
\text { media filter }\end{array}$ & MVC, MED, or TVC \\
\hline
\end{tabular}


Table C2 shows the result for Imperial Valley. GDsalt favored membrane processes at 20\% water recovery and thermal processes for the $85 \%$ recovery, illustrating the transition caused by the specified level of water recovery. Mechanical vapor compression was a viable option under both conditions.

Table C2. GDsalt results for Imperial Valley - effect of specified recovery

\begin{tabular}{|l|c|c|c|c|}
\hline \multirow{2}{*}{$\begin{array}{l}\text { Imperial Valley } \\
\text { Source Water }\end{array}$} & \multicolumn{2}{|c|}{$\mathbf{8 5 \% \text { Water Recovery }}$} & \multicolumn{2}{c|}{ 20\% Water Recovery } \\
\cline { 2 - 5 } & Pretreatment & Desalination & Pretreatment & Desalination \\
\hline $\begin{array}{l}\text { Surface Water } \\
\text { TDS }=44,100 \\
\mathrm{mg} / \mathrm{L}\end{array}$ & $\begin{array}{c}\text { Acid cation IX (H), } \\
\text { Media filter } \\
\text { GAC }\end{array}$ & MVC, MED, or TVC & $\begin{array}{c}\text { Acid cation IX (H), } \\
\text { Media filter } \\
\text { GAC }\end{array}$ & $\begin{array}{c}\text { BWRO, SWRO, or } \\
\text { MVC }\end{array}$ \\
\hline $\begin{array}{l}\text { Geothermal Brine } \\
\text { TDS }=195,000 \\
\mathrm{mg} / \mathrm{L}\end{array}$ & $\begin{array}{c}\text { Media filter and } \\
\text { Acid cation IX (H) }\end{array}$ & MVC, MED, or TVC & $\begin{array}{c}\text { Media filter and } \\
\text { Acid cation IX (H) }\end{array}$ & $\begin{array}{c}\text { BWRO, SWRO, or } \\
\text { MVC }\end{array}$ \\
\hline
\end{tabular}

Table C3 lists the cases for Hidalgo County, TX. The groundwater TDS was relatively low, less than 5,400 $\mathrm{mg} / \mathrm{L}$ for all cases; thus, the tool selected membrane processes for all cases. The results of the Hidalgo County surface-water case mimicked that for the $25^{\text {th }}$-percentile Imperial Valley groundwater case, which also had a relatively low TDS level.

Table C3. GDsalt results for Hidalgo County, TX groundwater - effect of specified recovery

\begin{tabular}{|c|c|c|c|c|}
\hline \multirow{2}{*}{$\begin{array}{l}\text { Source Water } \\
\text { Hidalgo County } \\
\text { Groundwater }\end{array}$} & \multicolumn{2}{|c|}{ 85\% Water Recovery } & \multicolumn{2}{|c|}{$20 \%$ Water Recovery } \\
\hline & Pretreatment & Desalination & Pretreatment & Desalination \\
\hline $\begin{array}{l}25^{\text {th }} \text { percentile } \\
\text { TDS }=1,300 \mathrm{mg} / \mathrm{L}\end{array}$ & Media filter & BWRO, SWRO, or MVC & Media filter & BWRO, SWRO, or MVC \\
\hline $\begin{array}{l}\text { Mean } \\
\text { TDS = 3,300 mg/L }\end{array}$ & Media filter & BWRO, SWRO, or MVC & Media filter & BWRO, SWRO, or MVC \\
\hline $\begin{array}{l}75^{\text {th }} \text { percentile } \\
\text { TDS }=5,400 \mathrm{mg} / \mathrm{L}\end{array}$ & Media filter & BWRO, SWRO, or MVC & Media filter & BWRO, SWRO, or MVC \\
\hline
\end{tabular}




\section{Appendix D - Case Study Provided to CSM Senior Design Class}

\section{Design of a Geothermal Desalination Process for Potable-Water Production}

Project Overview: Geothermal resources and water scarcity are two common features of the western United States. Low-temperature $\left(<100^{\circ} \mathrm{C}\right)$ geothermal resources have wide geographic distribution, but are highly underutilized because they are too inefficient for power production. A potentially useful application of low-enthalpy geothermal energy - from low-temperature resources or rejected heat from high-temperature geothermal power plants-is the desalination of impaired waters (e.g., brackish surface or groundwater, seawater, or brines co-produced from oil and gas operations). Desalination of impaired water has the potential to mitigate the substantial declines in western water resources that have been observed in the last few decades.

This study will explore if heat from low-enthalpy geothermal sources can either be directly utilized in thermal desalination processes (e.g., multi-effect distillation) or indirectly used to generate small-scale power generation necessary for electricity-based desalination processes (e.g., nanofiltration (NF) or reverse osmosis (RO)). The project will include interaction with engineers at the National Renewable Energy Laboratory (NREL) and CSM's Advanced Water Technology Center.

Selection of water-desalination processes is a complex task, and it can include dozens of desalination and pretreatment technologies. It involves the development of a treatment train that comprises a desalination technology and pretreatment process (in both cases, there can be one or more technologies) based on input water composition and quantity and the desired end-use water quality. A computerized decision support tool is a good way to "automate" this process to identify the best candidate treatment technologies and trains based on parameters such as water quality, treatment efficiency, available energy, energy-demand limitations, and overall economics (i.e., capital and O\&M costs). A joint project between NREL and CSM has developed GDsalt, a geothermal desalination decision tool. This project will use GDsalt and NREL's geothermal exploration and analysis tools to aid in the design of a treatment system to produce potable water from brackish water in the western U.S.

Project Deliverables: The study will examine desalination of brackish groundwater and/or surface water in California's Imperial Valley — a region with severe water shortages and strong geothermal resources. A substantial amount of support material is available for this project. Your team will simulate water-treatment trains in Aspen based on the suggestions of GDsalt. The objective is to simulate each of the water-treatment processes in the train and the entire treatment train, analyze thermal-energy demands, electric-energy demand, and the economic viability of the processes.

Tasks to be completed in this assignment include:

- Learn to operate GDsalt and generate water-treatment trains combining thermal and electrical energy from geothermal power plants (responsibility of CEE). NREL staff will assist the team with the usage of NREL's System Advisor Model and Geothermal Prospector to estimate geothermal system cost. 
- Generate detailed process designs for one base case at several water-recovery rates (increasing water recovery from the same source of water, leading to higher concentration of the brine), including detailed water and energy flows, product recovery, and waste generation.

- Complete detailed ASPEN simulations for the treatment train.

- Propose and evaluate two alternative designs that improve the process efficiency, utilization of geothermal thermal energy, and/or maximize clean-water recovery/production.

- Estimate capital and operating costs for the base-case design and two options (20-year economic life) for a facility to produce potable water. Provide installed system cost and cost per unit of product water. 


\section{Appendix E - Calculation of Levelized Cost of Heat}

The $\mathrm{LCOH}$ is calculated in a spreadsheet using the formulae for fixed charge rate (FCR) as described in SAM version 2015-06-30, which is based on reference [29]. The explanation below is excerpted from SAM's help menu.

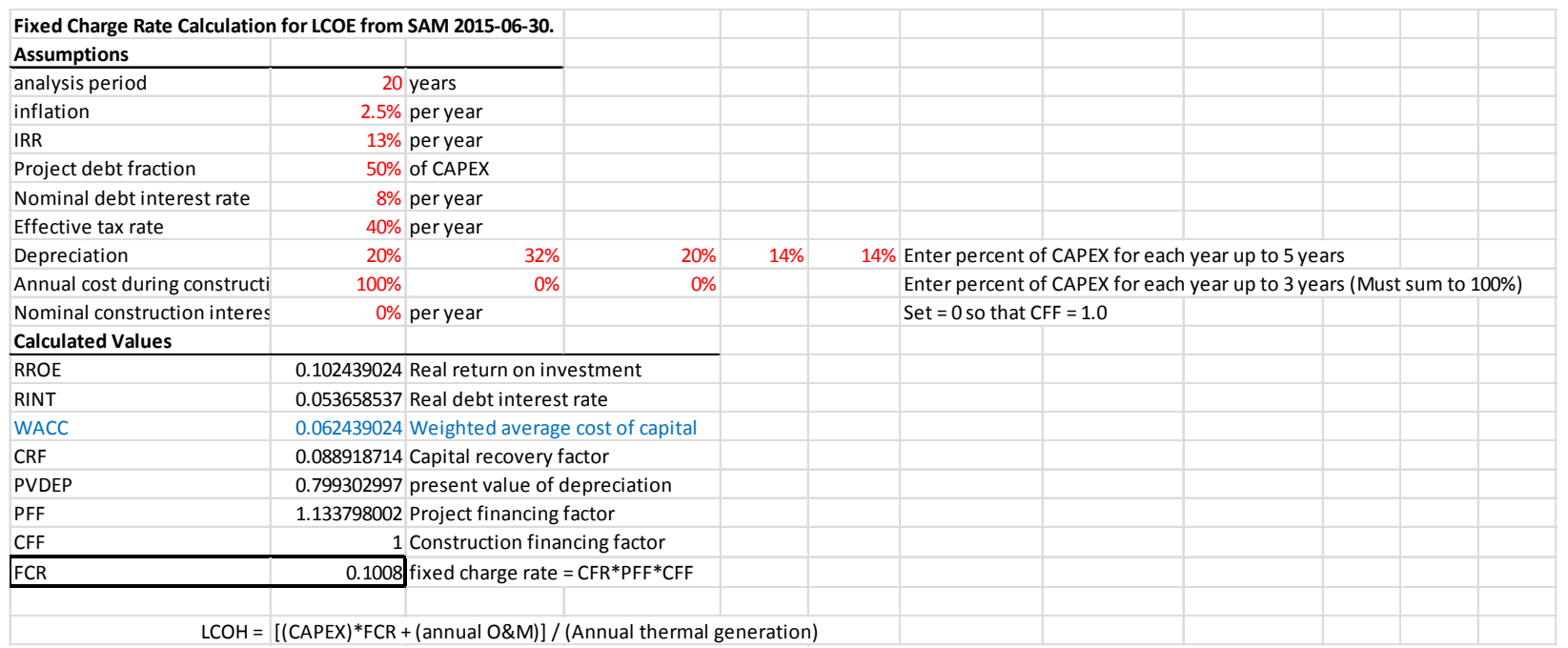

SAM's LCOE Calculator uses a simple method to calculate a project's levelized cost of energy (LCOE) using only the following inputs:

- Total Capital Cost, \$ (TCC)

- $\quad$ Fixed annual Operating Cost, \$ (FOC)

- Variable Operating Cost, $\$ / \mathrm{kWh}$ (VOC)

- $\quad$ Fixed Charge Rate (FCR)

- Annual electricity production, kWh (AEP)

The LCOE Calculator uses the following equation to calculate the LCOE:

$$
\mathrm{LCOE}=\frac{\mathrm{FCR} \times \mathrm{TCC}+\mathrm{FOC}}{\mathrm{AEP}}+\mathrm{VOC}
$$

The fixed charge rate is the revenue per amount of investment required to cover the investment cost. For details, see pp. 22-24 of reference [29]. This method is an alternative to the cash flow method used by SAM's other financial models. It is appropriate for very preliminary stages of project feasibility analysis before you have many details about the project's costs and financial structure. SAM does not contain a geothermal hybrid model, so direct use of SAM's other financial models is not possible.

\section{Capital and Operating Costs}

\section{Capital cost}

The project's total investment cost. 


\section{Fixed operating cost}

Annual operating costs that do not vary with the amount of electricity the system generates.

\section{Variable operating cost}

Annual operating costs in dollars per kilowatt-hour that vary with the amount of electricity the system generates.

\section{Summary}

The Summary values are the inputs to the LCOE equation. These values are calculated from the inputs you specify.

\section{Fixed charge rate}

The project fixed charge rate, or revenue per amount of investment required to cover the investment cost. Calculated from the financial details you enter.

\section{Capital cost}

The total overnight investment cost in dollars.

\section{Fixed operating cost}

The fixed annual operating cost in dollars. It is either the value you enter or a value that SAM calculates based on the value you enter in dollars per kilowatt.

\section{Variable operating cost}

The variable annual operating cost in dollars per kilowatt-hour that you enter.

\section{Financial Assumptions}

The fixed charge rate represents details of the project's financial structure.

\section{Calculate fixed charge rate}

SAM calculates the fixed charge rate from a set of financial assumptions. SAM uses the following equation to calculate the value from the capital recovery factor, project financing factor, and construction financing factor (see below for all equations):

$$
\mathrm{FCR}=\mathrm{CRF} \times \mathrm{PFF} \times \mathrm{CFF}
$$

\section{Fixed charge rate}

The project's fixed charge rate. Note that the value is a factor (between 0 and 1 ) rather than a percentage.

\section{Analysis period}

The number of years that the project will generate electricity and earn revenue.

\section{Inflation rate}

The annual inflation rate over the analysis period.

\section{Internal rate of return}

The project's annual rate of return requirement.

\section{Project term debt}

The size of debt as a percentage of the capital cost. 


\section{Nominal debt interest rate}

The annual nominal debt interest rate. SAM assumes that the debt period is the same as the analysis period.

\section{Effective tax rate}

The total income tax rate. For a project that pays both federal and state income taxes, where the state income tax is deducted from the federal tax, you can calculate the effective tax rate as:

$$
\text { TAX }=\text { STATE }+ \text { FED } \times(1-\text { STATE })
$$

\section{Depreciation schedule}

The annual depreciation schedule. The depreciation basis equals the project's capital cost.

\section{Annual cost during construction}

The annual construction cost as a percentage of the project's capital cost. If the construction period is one year or less, enter a single value. If it is more than one year, enter a schedule of annual percentages.

\section{Nominal construction interest rate}

The annual interest rate on construction financing.

\section{Capital recovery factor (CRF)}

SAM calculates this value from the inputs you specify as described below.

\section{Project financing factor (PFF)}

Factor to account for project financing costs. SAM calculates this value from the effective tax rate and depreciation schedule, as described below.

\section{Construction financing factor (CFF)}

Factor to account for construction financing costs. SAM calculates the value from the construction cost schedule, effective tax rate, and construction interest rate, as described below.

\section{Equations for FCR Calculation}

When you use the Calculate fixed charge rate option, SAM uses the following equations to calculate the financing factors.

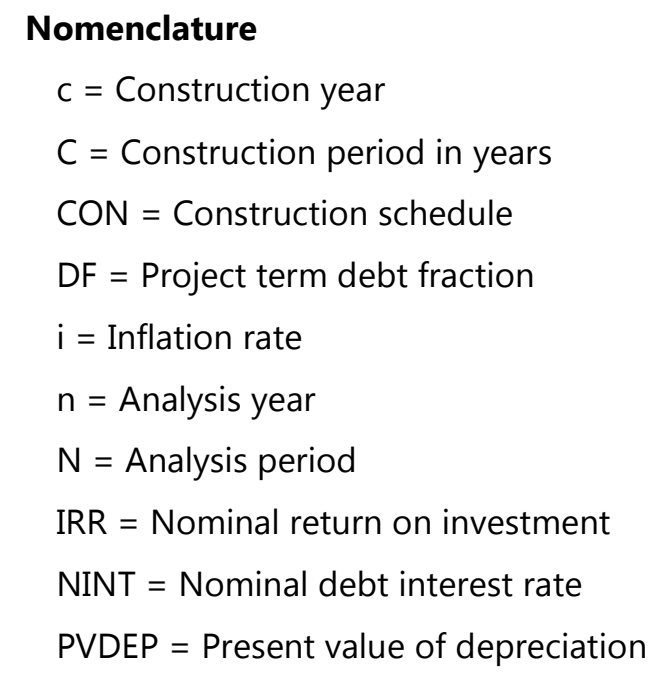


RINT $=$ Real debt interest rate

RROE $=$ Real return on investment

TAX = Effective tax rate

WACC $=$ Weighted average cost of capital (real)

The capital recovery factor (CRF) is a function of the weighted average cost of capital (WACC) and analysis period $(\mathrm{N})$ :

$$
\mathrm{CRF}=\frac{\text { WACC }}{1-\frac{1}{(1+\text { WACC })^{N}}}
$$

Where:

$$
\begin{gathered}
\text { WACC }=\frac{1+((1-\mathrm{DF}) \times((1+\mathrm{RROE}) \times(1+\mathrm{i})-1))+\mathrm{DF} \times((1+\mathrm{RINT}) \times(1+\mathrm{i})-1) \times(1-\mathrm{TAX})}{1+\mathrm{i}}-1 \\
\text { RROE }=\frac{1+\mathrm{IRR}}{1+\mathrm{i}}-1 \\
\text { RINT }=\frac{1+\mathrm{NINT}}{1+\mathrm{i}}-1
\end{gathered}
$$

The project financing factor (PFF) is a function of the effective tax rate and depreciation schedule:

$$
\mathrm{PFF}=\frac{1-\mathrm{TAX} \times \mathrm{PVDEP}}{1-\mathrm{TAX}}
$$

Where:

$$
\operatorname{PVDEP}=\sum_{\mathrm{n}=0}^{N} \frac{\text { DEP }_{\mathrm{n}}}{((1+\text { WACC }) \times(1+i))^{(\mathrm{n}+1)}}
$$

The construction financing factor (CFF) is a function of the construction cost schedule, effective tax rate, and nominal construction financing interest rate:

$$
\mathrm{CFF}=\sum_{\mathrm{c}=0}^{\mathrm{c}} \mathrm{CON}_{\mathrm{c}} \times\left(1+(1-\mathrm{TAX}) \times\left((1+\mathrm{CINT})^{(\mathrm{c}+0.5)}-1\right)\right)
$$

